Received 1 Jan 2019; accepted 12 April 2020.

Available online 30 April 2020

\title{
Bringing a City Together; Sociological Perspectives on Urban Resilience and Heritage Preservation
}

\author{
Dr. Amal Adel Abdrabo \\ Sociology Lecturer (PhD), Social Sciences Department, \\ Faculty of Education, Alexandria University, Egypt \\ amal.abdrabo@alexu.edu.eg
}

\begin{abstract}
David Harvey argues that: "the right to the city is far more than the individual liberty to access urban resources. it is a right to change ourselves by changing the city collectively. the freedom to make and remake our cities and ourselves," (Harvey, 2008). In this vein, this paper is about how people claim their own spatial space and practice their right to the public space as a new form of human rights. It nests itself under two themes, mobility, and civic engagement, discussing different sportive-cycling initiatives as a form of sustainable urban transportation that was initiated within the city of Alexandria through different forms of grassroots movements that aim to increase the quality of urban life. Additionally, this paper presents an attempt to document some of the informal initiatives launched by the citizens of Alexandria City in Egypt; to create a bond with their city and help preserve part of its identity within an ever-changing public space on which they have no control. One of the greatest shocks and stresses within the case of Alexandria city is the rapid urbanization through which the face of the city has been dramatically changed within the last few decades. However, the pressing question here is: How did the people of Alexandria City react to these urban changes? Have they practiced David Harvey's right to the city? To understand how the structure is changed through people's actions, the author depends on Anthony Giddens's 'structure-agency' duality to study different Alexandrian bottom-up initiatives of heritage preservation and urban resilience. The paper also derives its sociological analysis from Max Weber's theory on the city as appeared in his treatise in 1921 Die Stadt: Eine Soziologische Untersuchung (The City; a Sociological Study). The connection comes from putting Max Weber's Occidental City in parallel with the Contemporary Urban Alexandria, through juxtaposing the 5-Weberian features of the ancient and medieval city vis-à-vis the modern status quo of Alexandria City in Egypt. Methodologically, the author uses Ryo Terui, et al.'s model 'Visual Narratives of the Actantial Map,' known as the 'Actor-Networking Map,' in analyzing different public initiatives of heritage preservation and urban resilience. The findings ascertained new theoretical and methodological insights within the discipline of urban sociology.
\end{abstract}

\section{Keywords}

The Right to the City; Grassroots Movements; Urban Resilience; Fenced-Heritage; Gated-Public Space; Alexandria.

\section{Introduction- The Right to the City}

David Harvey argues that: "the right to the city is far more than the individual liberty to access urban resources. it is a right to change ourselves by changing the city collectively. 
the freedom to make and remake our cities and ourselves," (Harvey, 2008). In this vein, this paper is about how people claim their own spatial space and practice their right to the public space as a new form of human rights. It nests itself under two themes, mobility and civic engagement, discussing different sportive-cycling initiatives as a form of sustainable urban transportation that was initiated within the city of Alexandria through different forms of grassroots movements that aim to increase the quality of urban life. In other words, it is about how to bring a city together using bottom-up sportive initiatives, through the analysis of new forms of urban social movements in the course of the study of different sportive grassroots movements. In this vain, the following lines are to answer the following questions: How could different public initiatives represent a new form of urban resilience and a creation of bottom-up-sportive-cultural heritage? What are the Weberian features of the Ideal Type of the Occidental City that can be trailed to the contemporary urban-city of Alexandria? Based on Max Weber's perspective on the city along with Visual Narratives, the paper explores how the people of Alexandria use bottom-up-unique ways to claim their right to their own city and.

Historically, Alexandria, The Pearl of the Mediterranean, was the capital city of Egypt during the region of Alexander the Great, who built it in $331 \mathrm{BC}$, when Alexandria enjoyed an autonomous rule, independent economic system, and a sense of a distinct cultural identity (Sirry, 2018). Today, different actors are controlling the fate of the urban space in metropolitan Alexandria. Sirry argues that two of the most pressing urban challenges in Alexandria are the demolished heritage of historical buildings and the rising numbers of what Sirry calls "gated communities," (Sirry, 2018); however, it is called within this paper "gated Public spaces," or any fenced-non-residential areas. Moreover, Alexandria is suffering from myriad urban problems that surpass the demolishing of historical buildings. For example, the micro-buses operators are working without coordination with other transportation providers, i.e. public buses, trams, and trains. The public spaces within Alexandria's main street are occupied by street vendors who always cause traffic jams and causing extra loaded problems to the transit chaotic system already exists within the city fabrics. in addition, the city suffers from the scarceness of its public spaces; as "very few green spaces are available for citizens who lack recreational areas . . the Corniche is not pedestrian-friendly," (UNFPA \& MPED, 2018).

Theoretically, the literature on urbanity is loaded with myriad definitions of the terms, urban resilience and heritage preservation, either from a sociological or an architectural point of view. On one hand, Cultural Heritage has been defined as being "the outcome of human experiences within a dynamic social context" (Serageldin, 2008). The definition stresses the human component within the process of acquiring heritage within a vibrant milieu which highlights the industrious efforts of the people creating and re-creating their spatial sphere. On the other hand, there is the well-known definition of Urban Resilience provided by the UN-Habitat, as being "the measurable ability of any urban system, with its inhabitants, to maintain continuity through all shocks and stresses, while positively adapting and transforming toward sustainability" (UN-Habitat, 2019). Additionally, and thanks to the psychiatrist Serge Tisseron, we are now talking about "Societal Resilience", and not just limiting the process of resilience to urbanity. He argues that within a process of societal resilience a resilient system will emerge where people 
will be able to foresee early warnings, to prepare before hand, to resist, to recover, to rebound, to re-learn, to recover, and finally to move toward a new state of dynamic equilibrium by "mitigating the physical and psychological consequences of previous unforeseen events" (Martin-Moreau and Ménascé, 2018).

In Tisseron's speech on The Colloquium on Resilient Cities and Territories on September 2017, he introduced a holistic vision of Societal Resilience based on four waves that defining the term as appears in (Figure \# 1). He argues that the process of resilience should not be used as a holistic term; instead it should be divided into four alternative words. The first, 'resilience,' depicts individual's qualities as resilient people who enjoy either due to a genetic origin or an auxiliary environment for resilience. The second is with an 'a' instead of the 'e', 'resiliance,' which characterizes the process of resilience itself. It also conveys relationships of duality between people who would turn to be resilient based on the help and encouragement they receive from other sources. The third word, 'Resilience,' 'would be with a capital ' $R$ ' to designate the strength of the resilient process which conveys a capacity for reconstruction and rebirth after environmental, political, social, and economic shocks, crises, and traumas (MartinMoreau and Ménascé, 2018). Eventually, the former three waves will lead at the end to the creation of an entire system of societal resilience that can be called a 'Societal Resilience System.'

Figure (1) "Serge Tisseron's Four Waves of Resilience" reaching a societal resilient system.

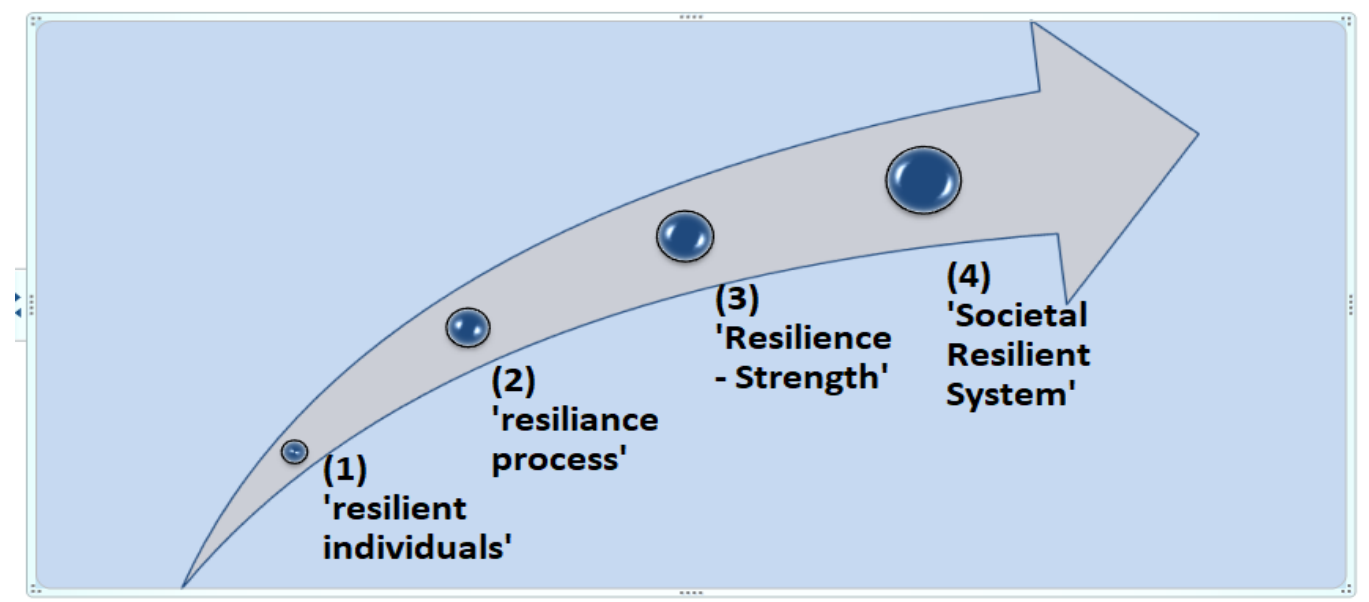

Source: the figure designed by the author

Applying Tisseron's societal resilience to the case of Alexandria city, does the city enjoy a societal resilient system? Can a state of an evolving dynamic equilibrium based on resilient people accelerate the resiliance process? Does Alexandria have a structureagent duality/structuration based on cooperation and sustenance among the people themselves as the inhabitants of the spatial space of their city, Alexandria? To answer the aforesaid question the research has to introduce its intake on the research method. Methodologically, the researcher uses Ryo Terui \& et al.'s model 'Visual Narratives of the Actantial Map,' known as the 'Actor-Networking Map,' as an ethnographic investigation that depends mainly on the photographic analysis. Within the field of Urban Area Studies, Ana Luz once said, "Situationists methods of exploring the city. Such methods 
usually recur to similar yet updated techniques: new psycho-geographies through digital imagery collages, visual essays of automatic writing and drawing, websites for city-walks and walktalks, specific designed computer languages. This entire urban buzz means that city dwellers are (re)claiming their 'place in space'," (Luz, 2006). Based on that, every photo and figure used in this paper is used in order to resemble an idea and to advocate a theoretical issue derived from the theoretical framework of Max Weber's ideal type of the city. Actantial Model' is derived from Aristotle's logic square, known as 'the square of opposition,' as a philosophical tool represented in the form of a diagram categorizing the distinction between opposite types of entities (Figures \# 2,3,4).

Figure (2) The Actantial Model based onThe Greimasian Semiotics

Actantial model - semiotic square

Parsons' interpretation of actant theory is derived and developed from Aristotle's writings about logic, which were described in diagrammatic form by Apuleius. This led to subsequent visualisations of the logic square, drawn during the middle ages and up to the 20th century. This was adapted by the narratologist A. J. Greimas to create his semiotic square.

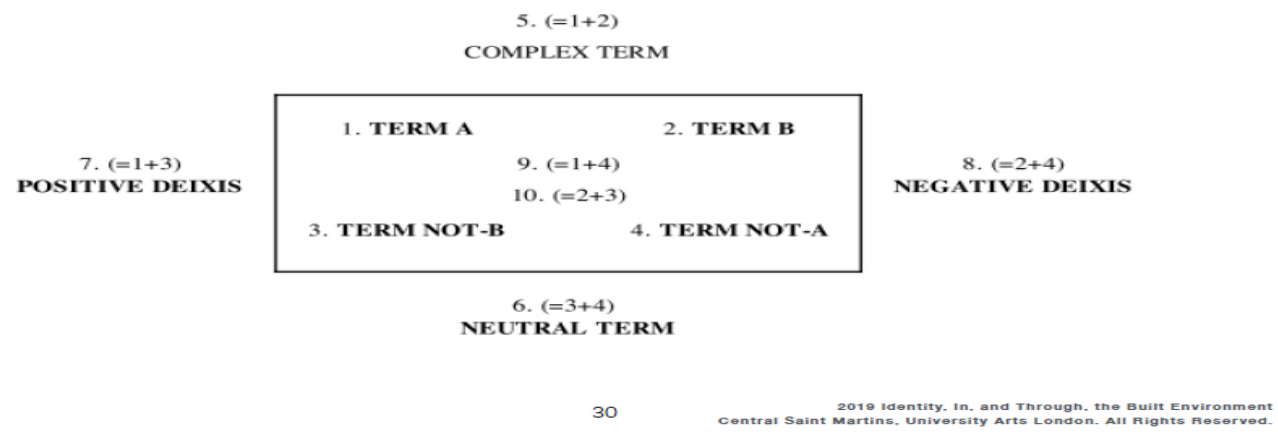

Source: the model originally is extracted from "Aristotle's Logic Square," the origin of Ryo Terui \& et al.'s model 'Visual Narratives of the Actantial Map,' known as the 'Actor-Networking Map,' (Terui, 2019).

Figure (3) The Greimasian Semiotic Square

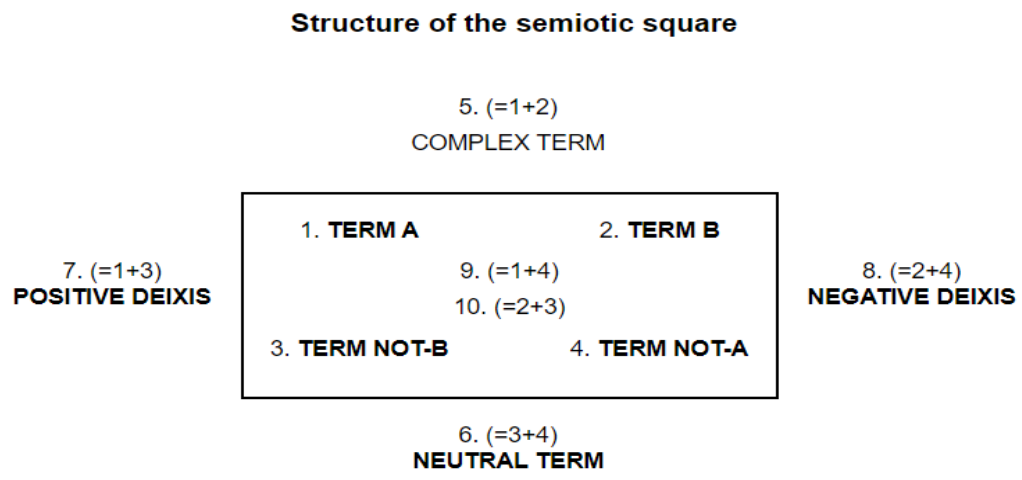

Source: (Hébert, 2006). 
Figure (4) Ryo Terui's Actantial Model

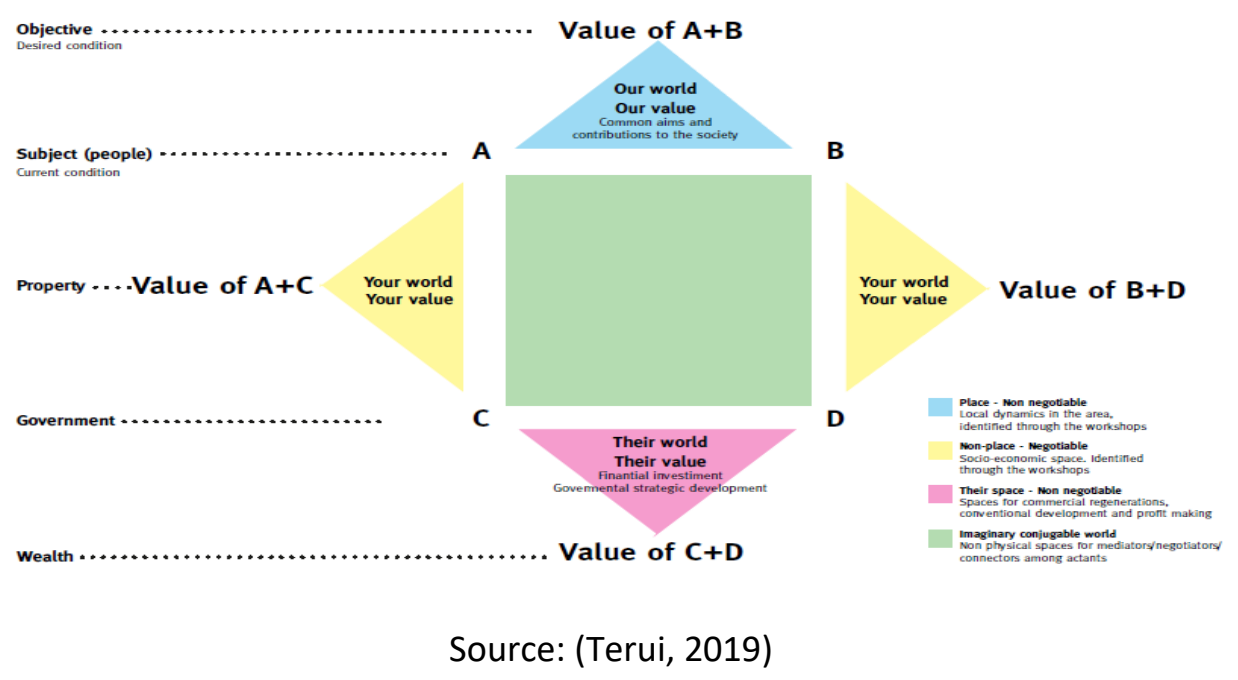

Based on the aforementioned, the research draws its methodological tool of visual narratives on the analysis of different public initiatives of heritage preservation and urban resilience within the city of Alexandria. The process of visual storyboarding started on December 2-3, 2019 under the supervision of Dr. Ryo Terui in order to identify the Actantial Map of different actors and bottom-up initiatives that may have led to the presence of a societal resilient system within the city of Alexandria (Figures \# 5-8). The paper identifies different actors of change based on the Weberian Perspective on the ideal type of the city along with the insights drawn from the Actantiality Mapping; as will be discussed thoroughly within the next section.

Figures (5) \& (5) The process of visual storyboarding and the building of the Actantial Map
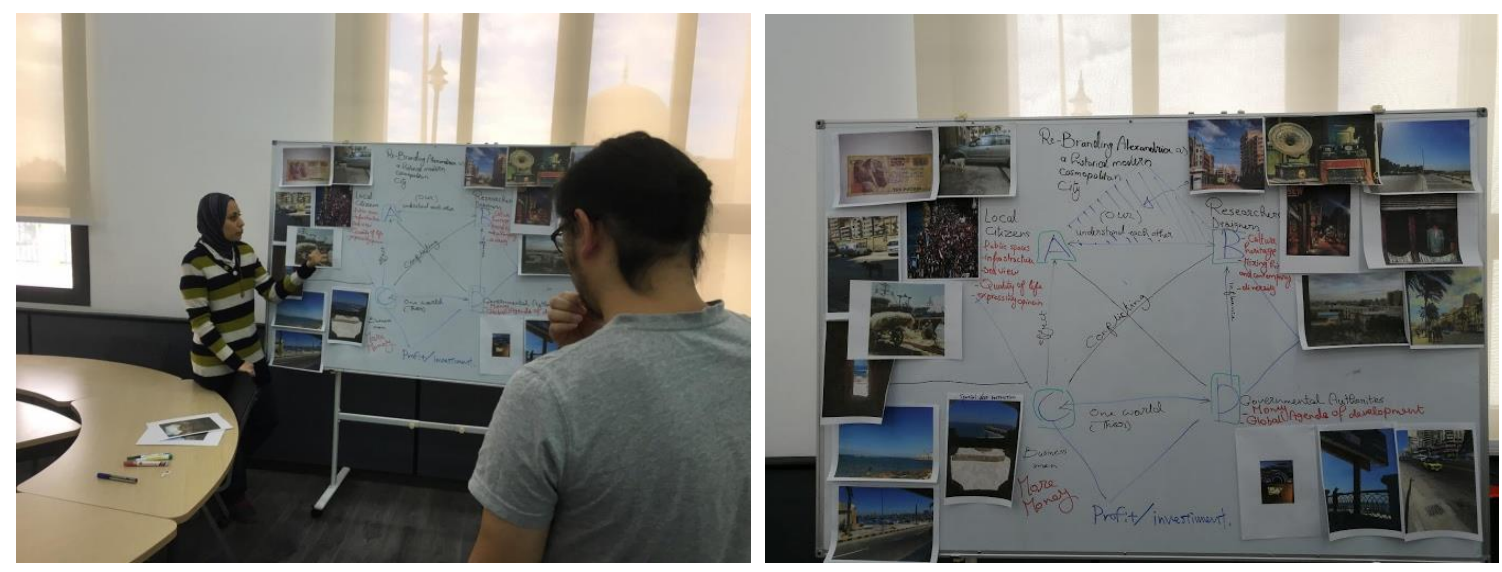

Source: Collective brainstorming during the process of visual storyboarding and the building of the Actantial Map, E-JUST (Dec, 2019). 
Figures (6) \& (8) The process of visual storyboarding and the building of the Actantial Map

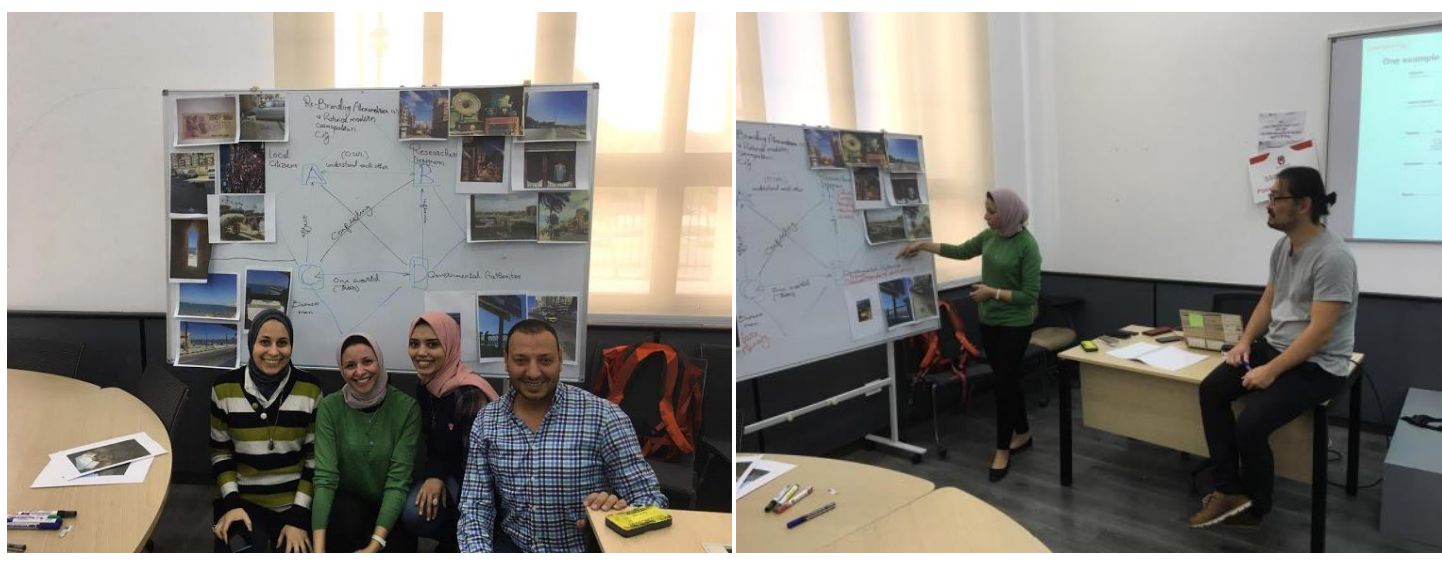

Source: Collective brainstorming during the process of visual storyboarding and the building of the Actantial Map, E-JUST (Dec, 2019).

\section{From Weber's Utopia to Reality: the Case of Alexandria City}

"The localization of strategic components of globalization in these cities means that the disadvantaged can engage the new forms of globalized corporate power," (Sassen, 2010)

The ideal type of the city is utopian as Max Weber argued that it cannot be found in reality as much it represents a mental construction of thoughts; as he said: "an ideal type is formed by the one-sided accentuation of one or more points of view. In its conceptual purity, this mental construct cannot be found empirically anywhere in reality. It is a utopia," (Borgatta and Montgomery, 2000). Along the previous lines, the term ideal type represents a benchmark that facilitates the comparative analysis of empirical phenomena based on an abstract-standard scale. It could be seen as a utopian model that was first coined by Max Weber as a way of comparison between Western and Eastern societies; as appeared in his landmark work Wirtschaft und Gesellschaft (Economy and Society) in 1922, which was published two years after his death. Weber believed that an urban community can only be found as an Occident phenomenon within Western Societies with the exception of some scattered Mesopotamia and Phoenicia societies in Near East. In this vein, he listed five-urban-community features that can be used as an ideal type of urbanity measurements, as follows: 1 . a fortification; 2 . a market; 3 . a court running with its autonomous law; 4 . a form of social association between a group of citizens; and finally 5. a form of religious and administrative autocephaly (Weber, 1969).

Consequently, it is worth mentioning that Weber's perspective of the city includes a certain type of cities where the inhabitants are able to adapt and respond to different forms of change using creativity and innovation as a way to overcome any shocks and crises, which is the core idea of Resilience even if the term "Resilience" was not used by Weber explicitly. Saskia Sassen managed to use Weber's theory on the Medieval City and apply it to what she called the Global City. She believes that "today, the localization of the global creates a set of objective conditions of engagement. by actors [for different actors especially those who were powerless and voiceless] struggling for recognition, entitlement, claiming their rights to the city." (Sassen, 2010). These claims are made 
through the agglomeration of strategic components where the dynamics of the current global cities produced new types of political actors. These actors are not only Weber's medieval-city urban residents, political leaders, merchants, and artisans, but also include new segments of urban actors who used to be invisible and powerless. Using innovative ways of resilience, they managed to create what Sassen called a 'distinctive presence' within the global sphere of today's global cities.

Going back to the paper sociological perspective and applying this 5-Weberian benchmark on the city of Alexandria reveals a quite similarity. Firstly, Alexandria Corniche was established during Mohamed Ali (1805-1848) region on Egypt. Alexandria waterfront (Corniche) was one of the Italian building styles brought to Egypt by the Italians Mario Rossi and Pietro Avoscani as a defending waterfront of the city between 1850's- 1950's (Turchiarulo, 2009). Secondly, soon after being founded in 331 BC during Alexander the Great era, Alexandria was the capital of Egypt for over 1.000 years and it was known as a trade center within the Mediterranean region due to its two harbors and its various types of markets that constructed the city as a Mediterranean-trade-focal point since the Hellenistic Era and the Ptolemaic region in Egypt. According to the Central Agency for Public Mobilization and Statistics (CAPMAS), Alexandria population is estimated to reach 5.328.264 inhabitants by the end of 2019 equally divided between males and females (please refer to: Barthel et al., 2017; UNFPA \& MPED, 2018). Thirdly, during the Greek and Roman times many temples to worship the god Serapis; one of these temples was The Serapeum that was famous as one of the colonnaded courts in ancient Alexandria (Escoffey, 2012). Fourthly, the fishing port and the city commercial activities and markets as a port to export grains coming from the Delta and import different goods to Egypt have witnessed the emergence of the Alexandria cultural identity within the central public space of the old city. Finally, the Coptic Orthodox Church of Alexandria was established by Saint Mark the author of the oldest canonical Gospel used by both St. Matthew and St. Luke, who came to Alexandria in the first or the third year of the reign of the Roman emperor Claudius, either in A.D. 41 or in A.D. 44. In this regard, the Coptic Church in Alexandria managed to create a religious autocephaly away from the Western Catholic Church led by the Pope, the Bishop of Rome (Meinardus, 2002).

Based on the aforementioned, the paper identifies different actors of change based on the Weberian Perspective on the ideal type of the city with the help of the Actantiality Mapping (Figure \# 9). The first category of actors is represented within the local citizens, who are hoping to enjoy open public spaces, sea view, improved infrastructure of the streets, and above all a better quality of life. The second category, who on understands with the local citizens, is represented in researchers (sociologists, anthropologists, architects, designers, etc.). Researchers mainly work for a better understanding of the society from different perspectives and dimensions. This better understanding may lead to the implantation of cultural diversity, social cohesion, and sustainable development. However, researchers do not work without restraint as they are influenced by the governmental authorities, the third category of actors. The governor and local city council are global-development-agenda abiding entities who are always 'up-top' within the hierarchy of authorities. The government has mutual interest with other stakeholders, 
businessmen, who share together the pursuit for a better investment sphere leading to more economic profits and money.

Figure (7) The Author's Model of Alexandria Actor-Networking Map," in analyzing different public initiatives of heritage preservation and urban resilience

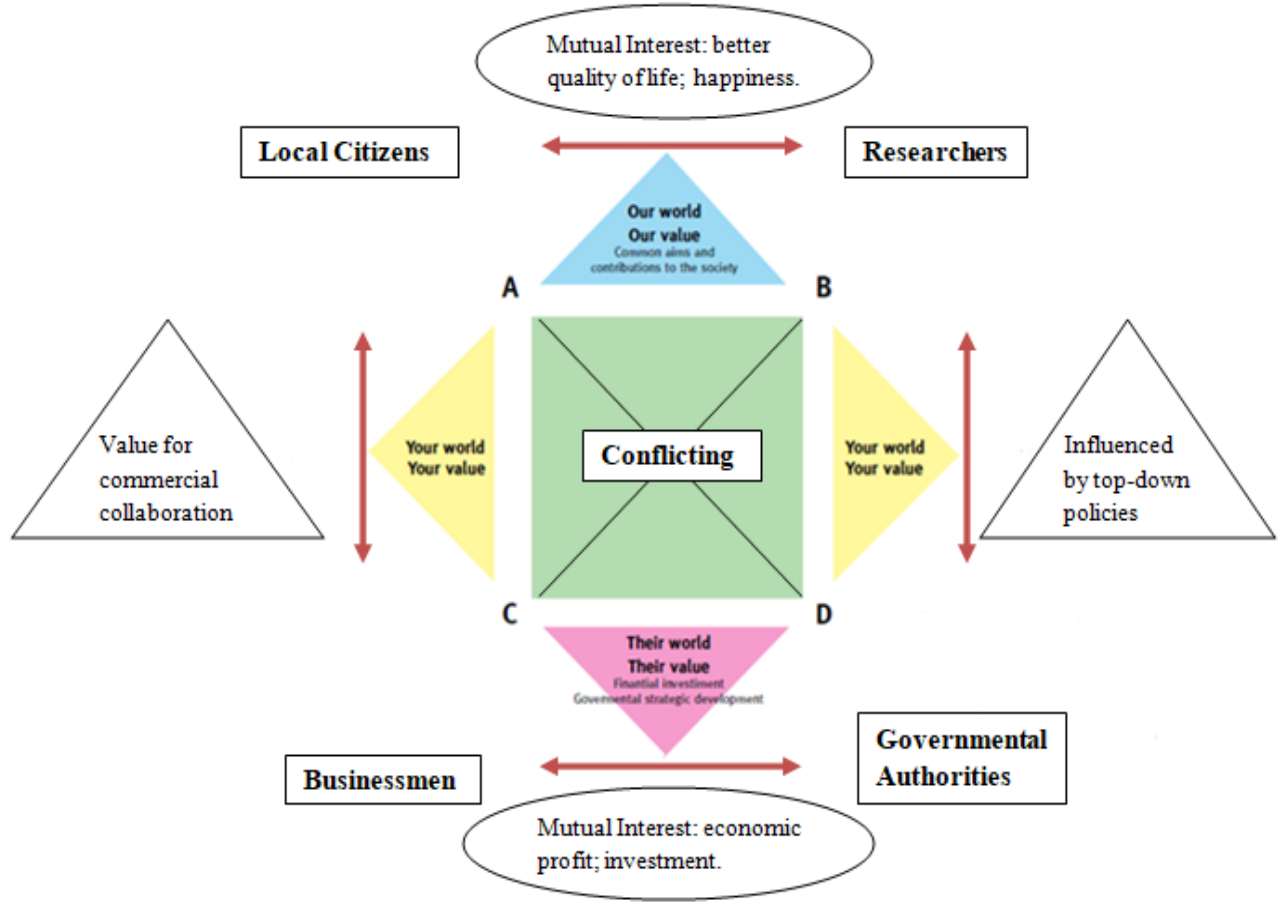

Source: The Author

Azza Sirry also identified different actors/ stakeholders who controls the fate of Alexandria among which different local, national and international entities can be identified; among which the central government in Cairo, local businessmen, the Alexandria Business Association (ABA), The Alexandria and Mediterranean Research Center at Bibliotheca Alexandrina (BA-Alex Med), the Cities Alliance, UN-Habitat, GIZ/PDP, USAID, The Swedish Institute Alexandria (SwedAlex), along other civil-society actors (Sirry, 2018). Despite this rich diversity of national and international actors, Sirry argues that all mega plans in Alexandria were executed without participation of the local actors and citizens of the city themselves. The local representatives of Alexandria cannot make any decision without consulting the central government in Cairo, which is the case with any other governorate in Egypt due to the central government system. Some of the previously mentioned international actors along with some European embassies managed to sponsor different events (biking/ cycling and cleaning the beach) in Alexandria. For instance, on the International Coastal Clean-up Day on 15 September 2018, The European Union (EU) Delegation in Egypt organized a 'beach-clean-up day' in Alexandria where 300 volunteers gathered to clean their city beaches (Figures \# 10-11). The volunteered event represented a form of urban resilience that brings a great segment of the city's citizens in an initiative of preserving a historical heritage of Alexandria represented in the city Cornich. 
Figure (8) 300 volunteers in the clean-up-beach day in 2018, Alexandria

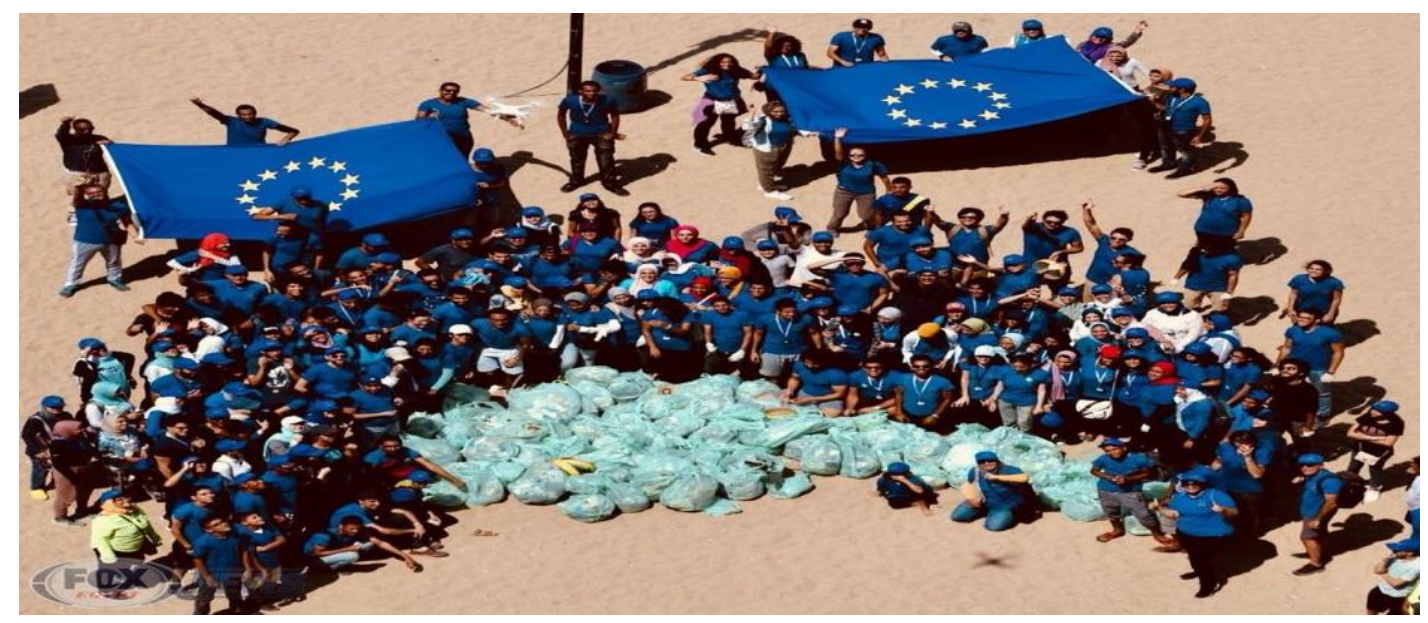

Source: Egypt Fox News, https://foxegyptnews.net/wpcontent/uploads/2018/09/20180915_122028.jpg

Figure (9) Representatives of the Local Governorate observing the clean-up-beach day in 2018, Alexandria

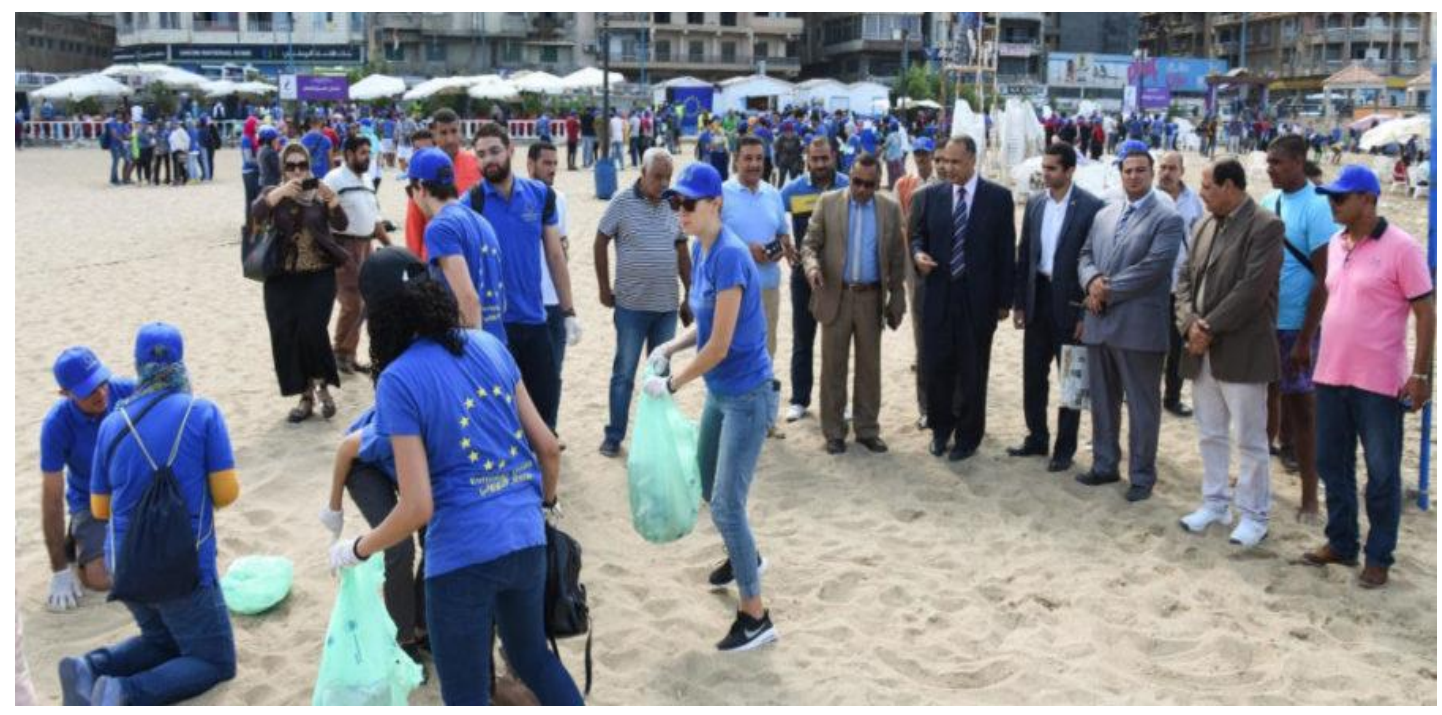

Source: WataniEn website, http://en.wataninet.com/wpcontent/uploads/2018/09/Image_1-8.jpeg

\section{Fenced-Heritage; Alexandria Corniche as a Spatial-Cultural Heritage}

"The city [Alexandria] should recover its prestige and greatness by emphasizing its architectural landmarks [restore its historical layers] and the Corniche road transformed into an attractive waterfront rather than the motorway it is today," (UNFPA\&MPED, 2018).

The Alexandrian architect May El-Tabbakh portrayed the severe damage made to the cultural-historical heritage of the cosmopolitan city of Alexandria as a site of different layers of history, a damage that changed the face of the city beyond recognition. As a very disappointed Alexandrian who feels frustrated for her city, El-Tabbakh says "The 
contemporary Alexandrian generation, to which I proudly belong, has grown weary in the recent times from the urban mess all over the place. For most of its sensuous beautiful buildings, pleasant gardens and even its peaceful sands are now being rapidly replaced by lifeless hideous concrete blocks with which it is difficult to harmonise or grow any lieu, really! There's nothing familiar about modern life in Alexandria anymore. Just another suffering rural city; faceless, nameless, emotionless compact masses..." (El-Tabbakh, 2014).

Academically, researchers are not supposed to use such long quotes; however, this previous quote of El-Tabbakh depicts the way the young generation in Alexandria misses their home-town; due to the dramatical severe process of privatization for all public areas and open spaces in Alexandria. Starting from Eastern side of the city with the famous historical Elmontaza Garden, then moving to the-once-was-public Sidi Bishr beaches, to Gleem Bay, Stanley cabins, and even the hideous Sidi Gaber bridge, all have no open spaces for the public to use without having to pay money to enjoy the 'sea view' a simpleconstitutional human right once before. Different local actors have stood to this brutal urban transformation, i.e. The Human and the City Center for Social Research (HCCSR)'s initiative "Alexandria Does not see the Sea" (facebook.com/HCSR19), (Figures \# 12-14).

Figure (10) Logo of Alexandria doesn't see the Sea Initiative

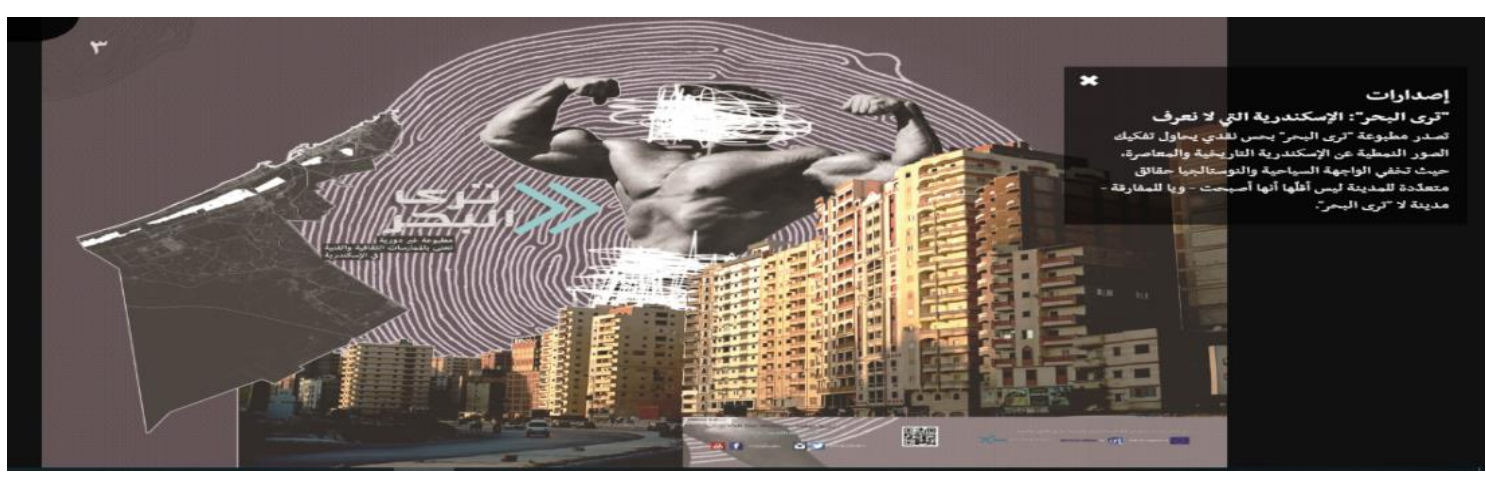

Source: Facebook page of HCCSR, 23 November 2018, facebook.com/HCSR19

Figure (11) Logo of Alexandria doesn't see the Sea Initiative

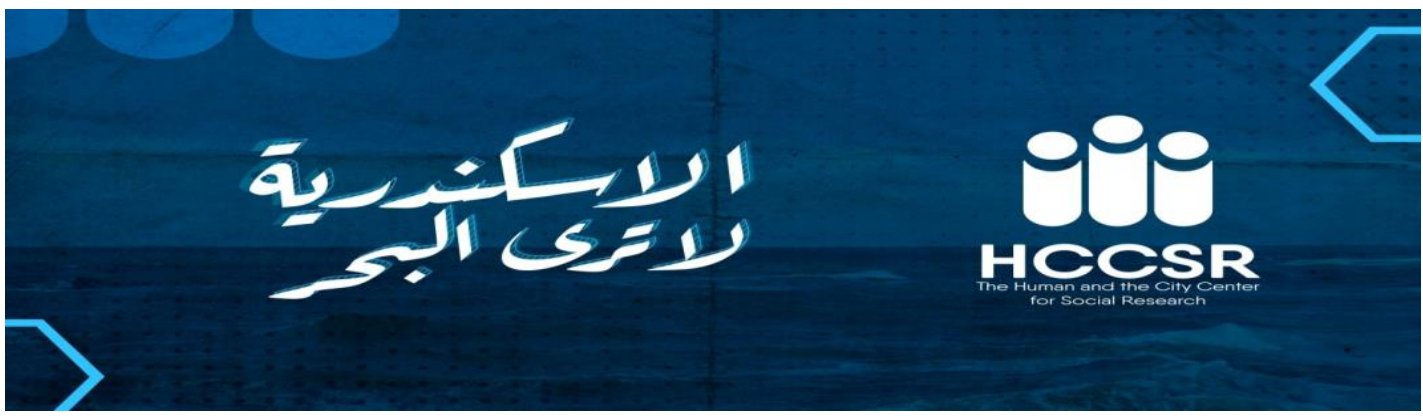

Source: Facebook page of HCCSR, 23 November 2018, facebook.com/HCSR19 
Figure (12) Alexandria Doesn't See the Sea going to the Administrative Judicial Court to stop fencing Alexandria Beaches

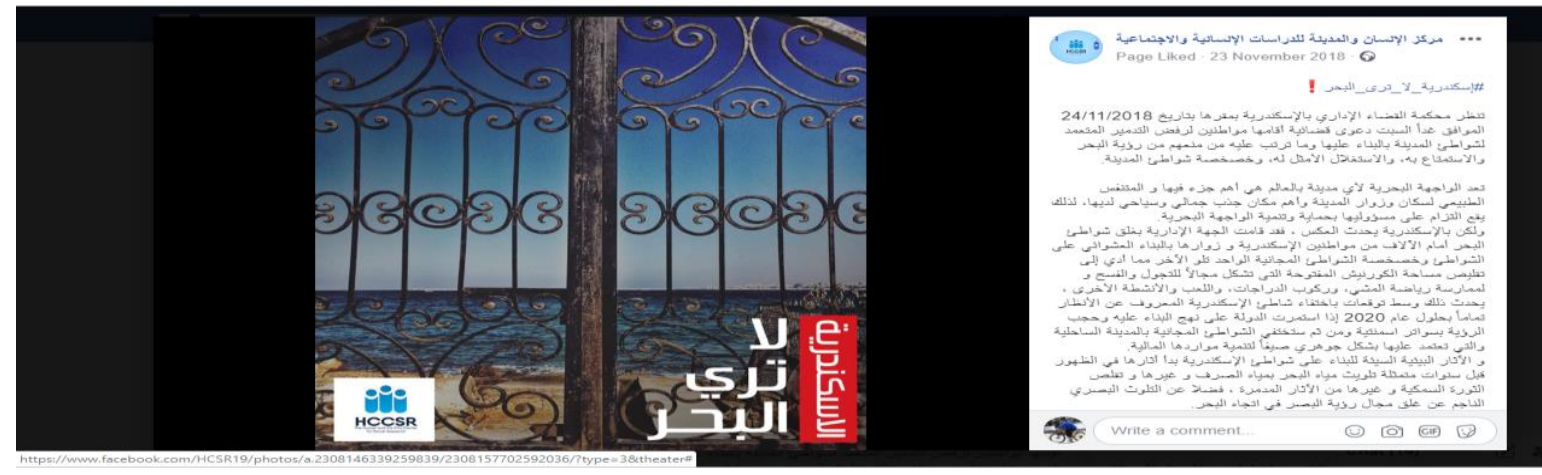

Source: Facebook page of HCCSR, 23 November 2018.

Another initiative of heritage preservation is called "أنقذوا الإسكندرية Save Alex," who released a campaign called Walls of an Exhausted City; in order to stop the brutal demolishing of historical buildings in Alexandria (Figures \# 15-16).

Figures (13) \& (16) Walls of an Exhausted City Initiative and Save Alex Initiative
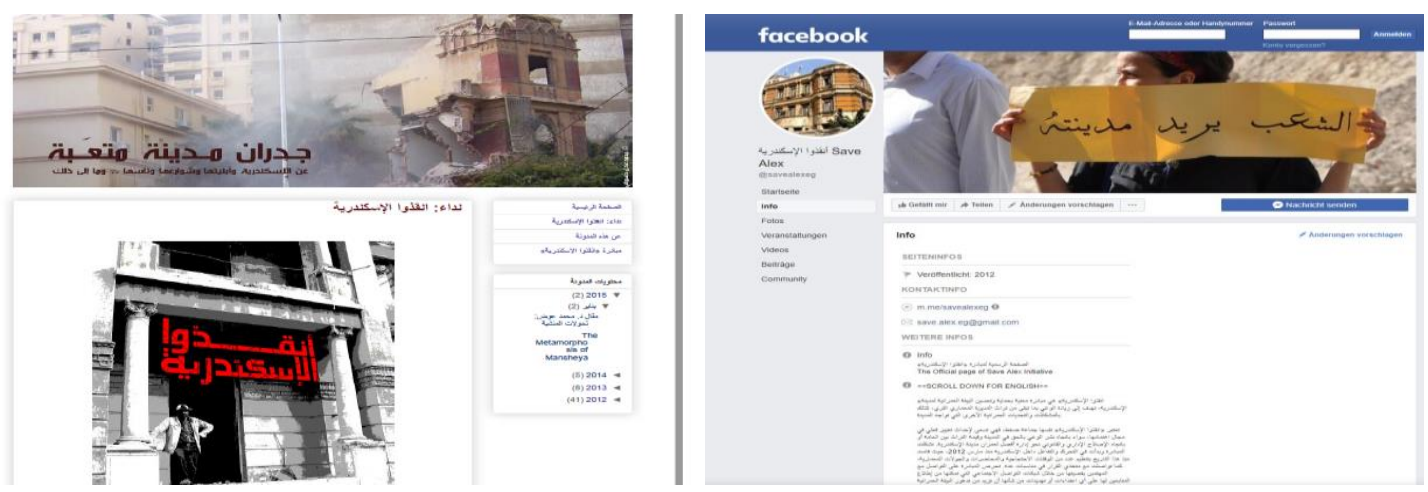

Source: Walls of an Exchausted City's website: http://thewallsofalex.blogspot.com/ (November, 2018) \& Save Alex's Facebook page: https://www.facebook.com/savealexeg/ (November, 2018)

Another bottom-up-interventional initiative is called "See The Sea," represents an interactive electronic platform that deals with cultural and artistic practices and contemporary urban changes in the city of Alexandria. The initiative is a project supported by the International Channel France and the Walls Foundation for Arts and Development (Figure \# 17).

Figure (14) Logo of See the Sea Initiative

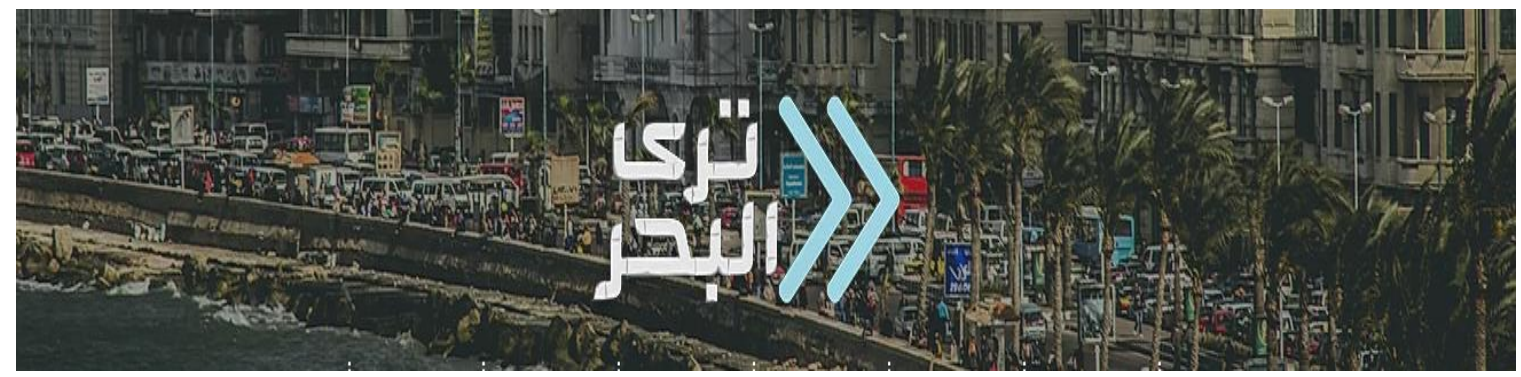

Source: See the Sea's website: https://www.taralbahr.com/about, November, 2018. 


\section{Gated-Public Space; the Case of Bibliotheca Alexandrina (BA) as a Fenced-Cultural Heritage.}

"the phenomenon of walled cities and gated communities represents a new fortress mentality growing". (Blakely and Snyder 1998)

The case of Alexandria Library (Bibliotheca Alexandrina- BA), as a knowledge-cultural hub that is located in the middle of a vibrant big urban city as the city of Alexandria, resembles a historical heritage for the people in Alexandria. BA was opened for public back in 2002 to occupy the area in front of Alexandria University Campus for Social Sciences. It was surrounded by an open area free for public access, then, due to security reasons this open area was heavily loaded by security restrictions that caused the minimization of the public access to this cultural and knowledge space affecting the role of BA as a knowledge precincts serving public. For example, BA was an open space for different cultural, sportive, public activities (especially within its exterior plaza) which are still running but under a highly security consideration that sometimes hinder the fully engagement of public access to this knowledge-cultural space. Through reviewing old pictures of it extracted from the internet we can witness the existence of only cars' barriers like the ones put in pedestrian streets with the existence of one security guard (Figures \#18-19). As figure \# 18 reveals the statues of Alexandria Library at its beginning before putting heavy security barriers. The picture depicts in front of the library a standing security man on the other side of the Corniche with no other barriers or fences around the premises. Furthermore, figure \# 19 depicts an old photo of BA from the other side in fornt of the university campus, before putting heavy security barriers.

Another photo that shows 'human fence' around the library created by ordinary citizens in order to protect their library during the period of political unrest after 2011 (Figure \#20) under the name "this is our library". Over the years, we started to witness increasing of the barriers and fences surrounding the library (Figure \# 21).

Lately and during the field visits (2017), the researcher remarked that the BA authorities have reinforced the barriers surrounding the whole area of the library in the form of three different fences, two points for security check outside the library, and other two inside the library area (Figure \# 22). Increasing security measures is fundamental during political upheavals, but having it as a permanent state has different social consequences in terms of public engagement with the public spaces around the city; which affects on the long run the city-cultural identity and social cohesion. That could affect the people's belonging to the city and affects the way they deal with their spatial surroundings, i.e. increasing of solid waste to be thrown in the street, increasing of vandalism acts of public writings on the walls, and a general public careless of respecting the human-spatial surroundings. This could put their identity as Alexandrians in danger, as people who belong to the city of Alexandria and have the right to enjoy their city in every possible way. 
Figure (15) An Egyptian policeman stands in front of the Bibliotheca Alexandrina in Egypt's Mediterranean port city of Alexandria Oct. 162002

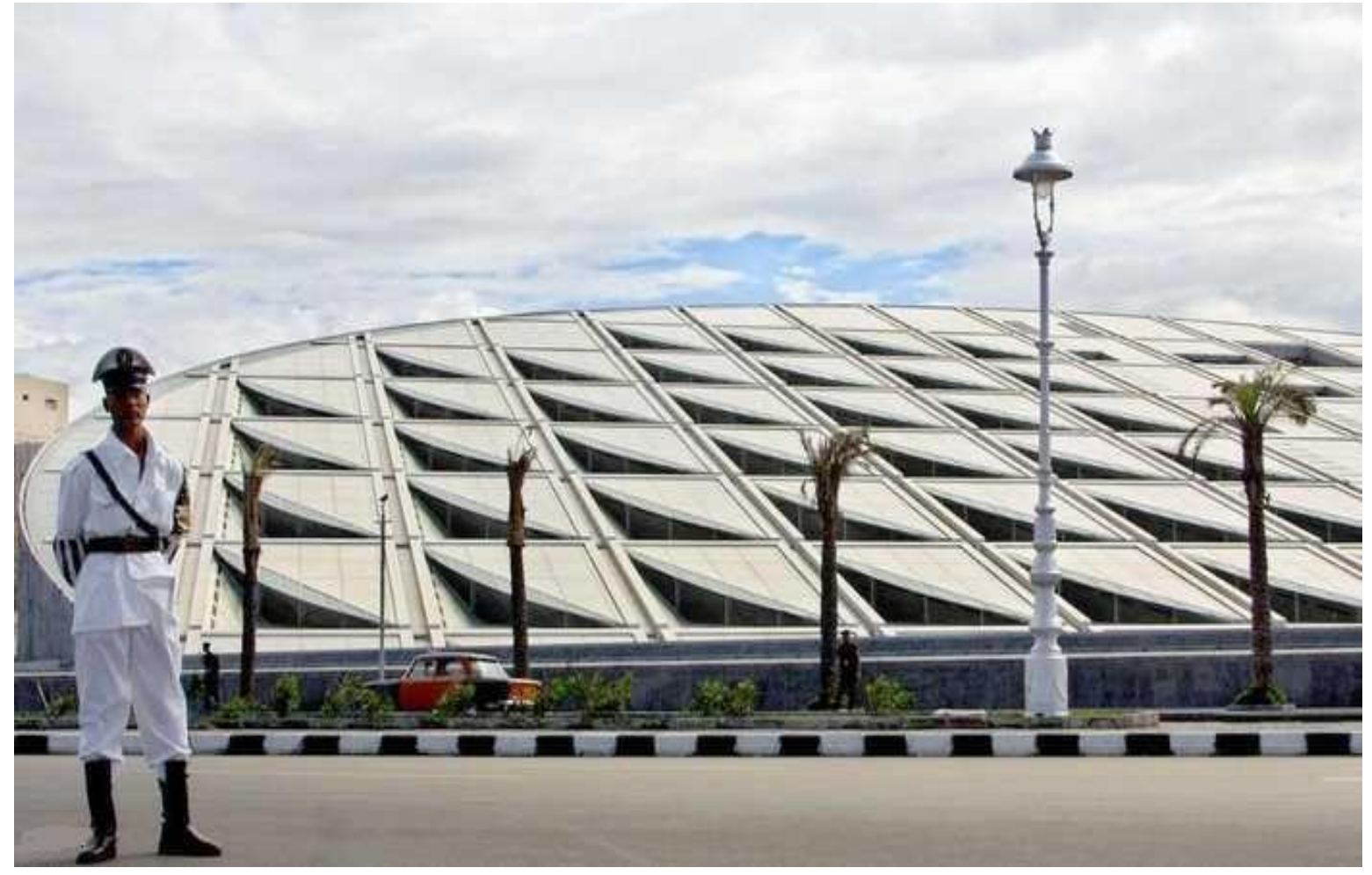

Source: Photo by: Marwan Naamani, https://globalnews.ca/news/1481801/the-worlds-coolestlibraries/

Figure (16) The Bibliotheca Alexandrina from the University Campus Side

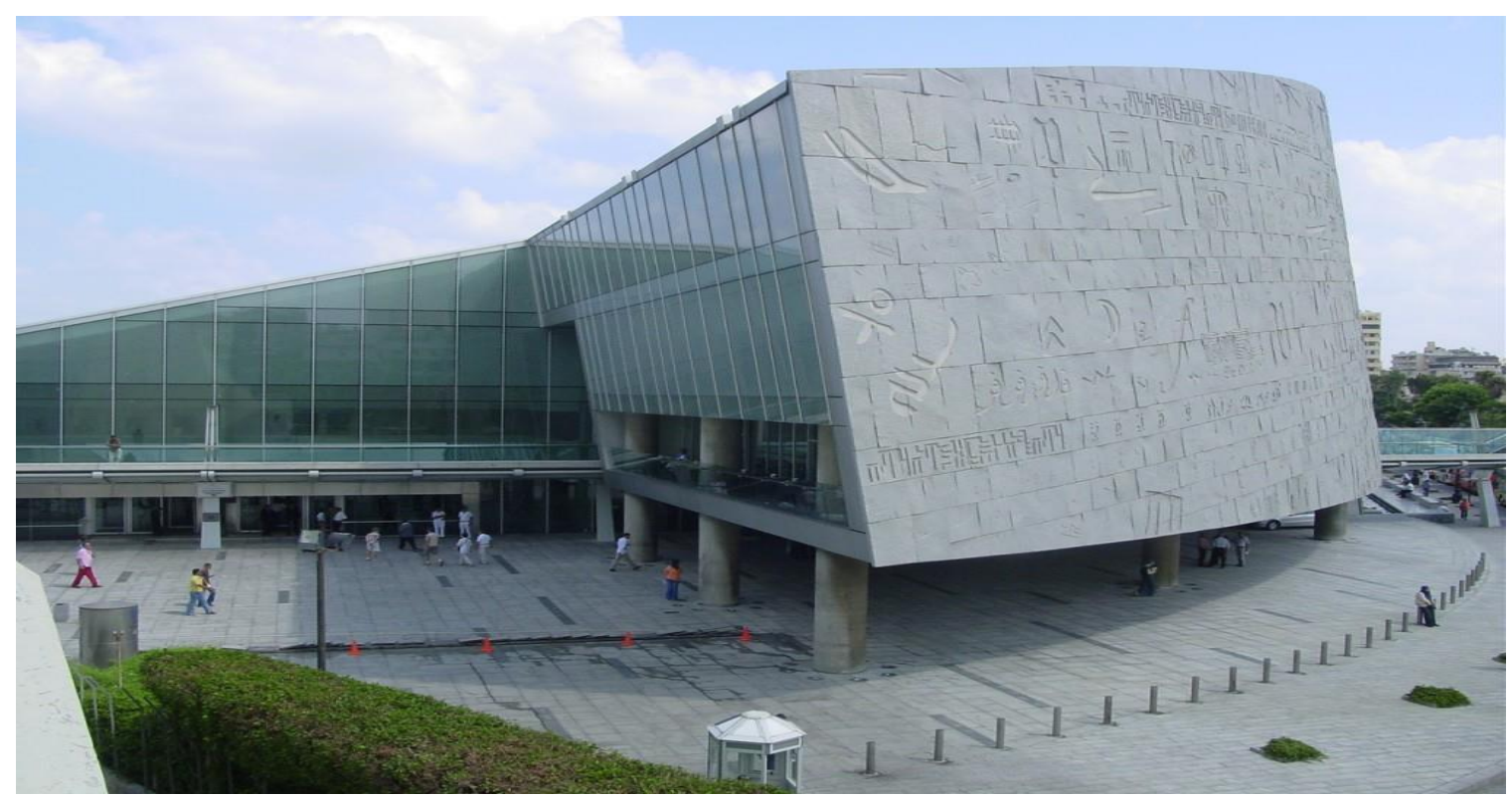

Source: Wikipedia, The Bibliotheca Alexandrina,

https://upload.wikimedia.org/wikipedia/commons/thumb/5/59/Bibliotheca_Alexandrina_plaza _003.jpg/220px-Bibliotheca_Alexandrina_plaza_003.jpg. 
Figure (17) This is our Library, Ordinary Citizens Protecting the Library against Intruders in 2011

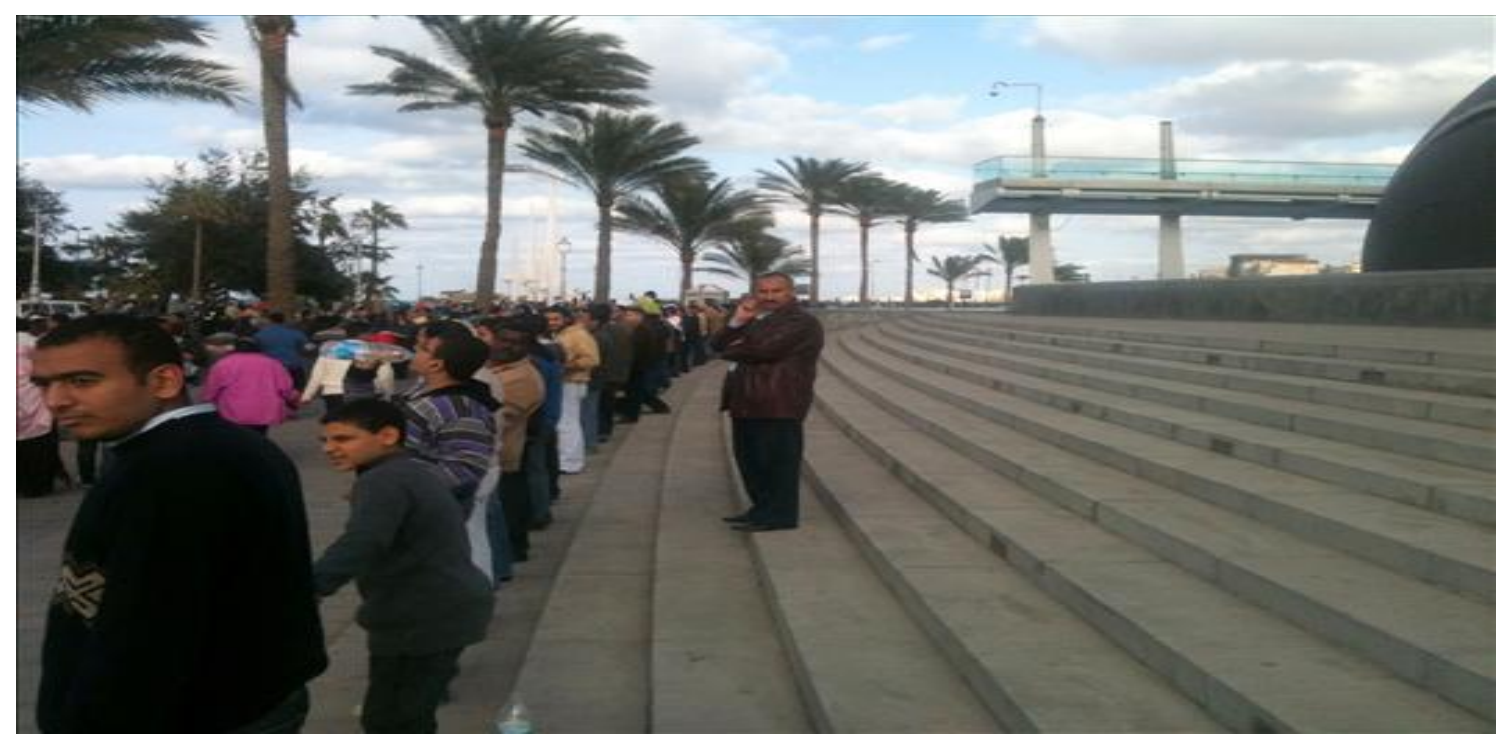

Source: Page Description "Demonstrators protect the Library of Alexandria by joining hands as marchers pass by. "What happened was pure magic," says the head of the library. Bibliotheca Alexandrina. February 24, 201112:01 AM ET. Link: https://media.npr.org/assets/img/2011/02/23/library_customf02c64aca9e833668e12c1a72f5d911f2eb9f686-s800-c85.jpg.

Figure (18) Increasing another Security Fence around BA area

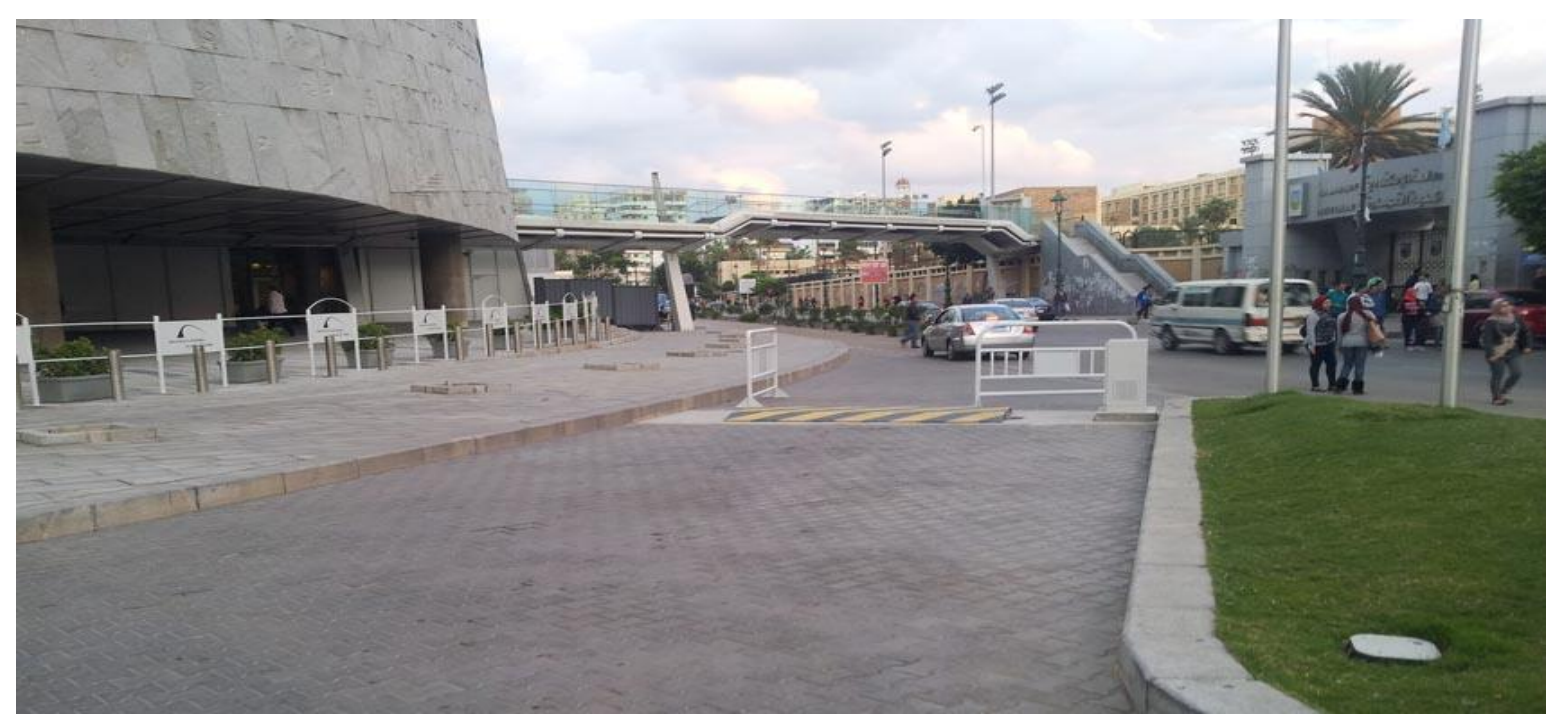

Source: ALEXANDRIA LIBRARY, EGYPT, https://tiso-blockers.com/reference-list/110-alexandrialibrary-egypt@www.tiso-blockers.com. 
Figure (19) Three more Security Fences surrounding the Library Area

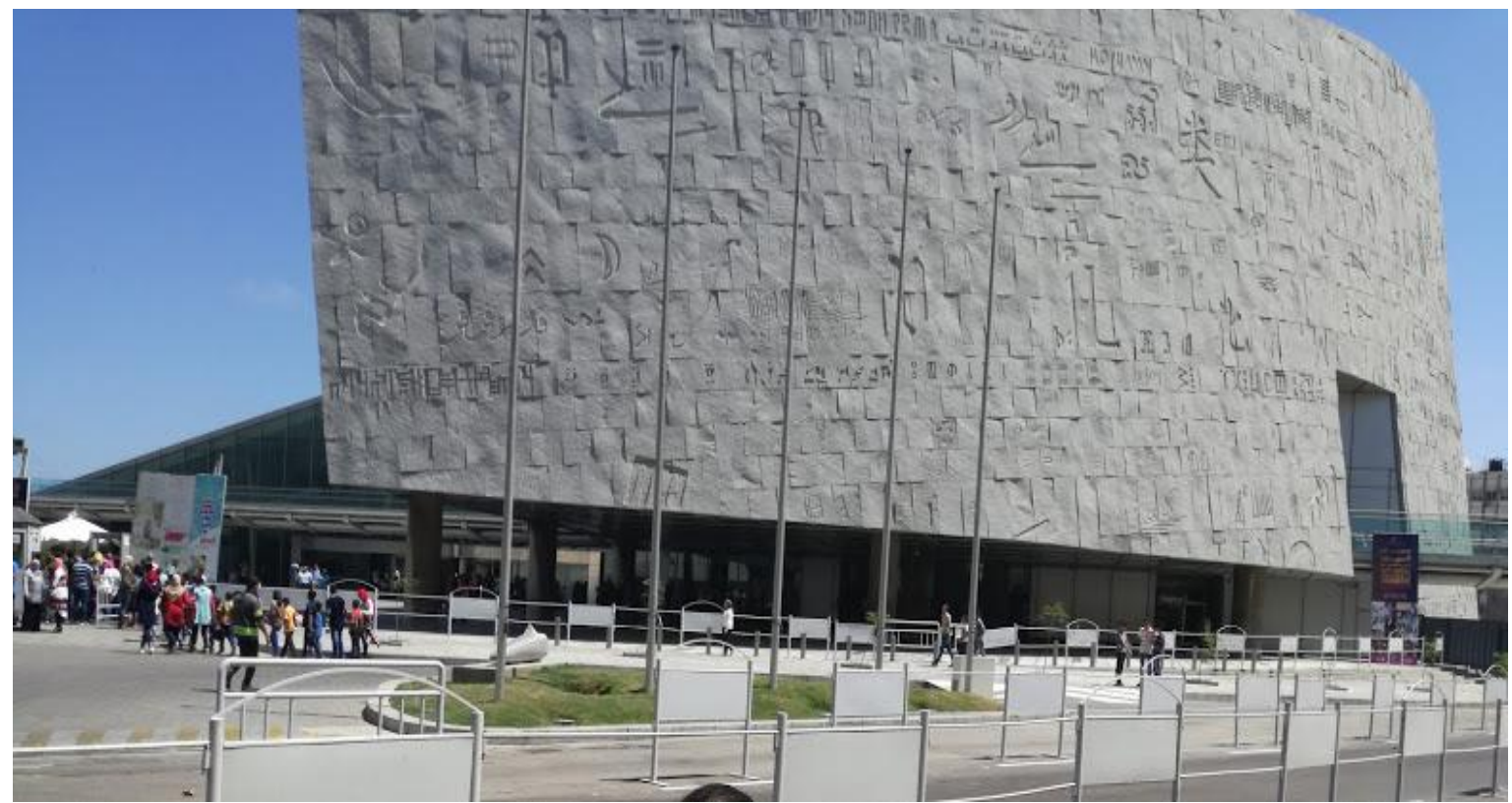

Source: The Author, August 2017.

However, despite the fact that BA is surrounded, nowadays, by intense security barriers, but we cannot claim to have it only as a fenced-ghost public space; because it hold many public events that involve a huge public access to its main building, other facilities, interior areas, and exterior plaza and also because it is located in the heart of Alexandria city (Figures \# 23-25).

Figure (20) Sportive public activities within BA Plaza

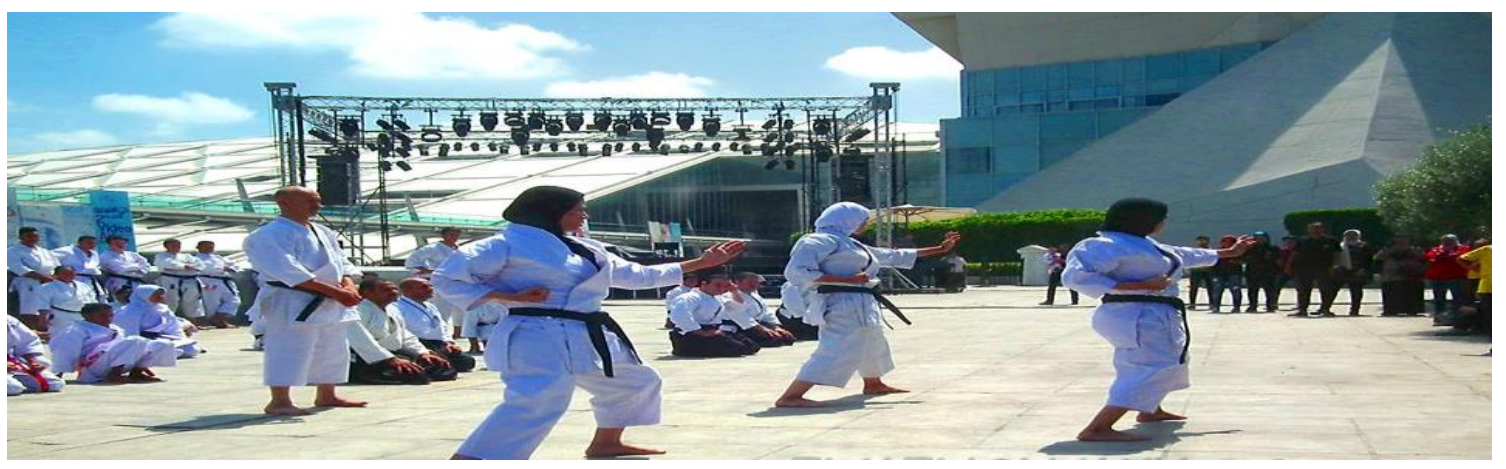

Source:https://lh3.googleusercontent.com/oDtZNYTEieUoQ1BhoOFINqZuqyp3B65ak1BUUdGiA 705I8B9fYcz4TcMl-MDYyLZ9kl-Sg=s136. 
Figure (21) Children Scouts Trips and Activities at BA Plaza, 26 July, 2016, كرنفال شعبى في احتفالات الإسكندرية بعيدها القومى

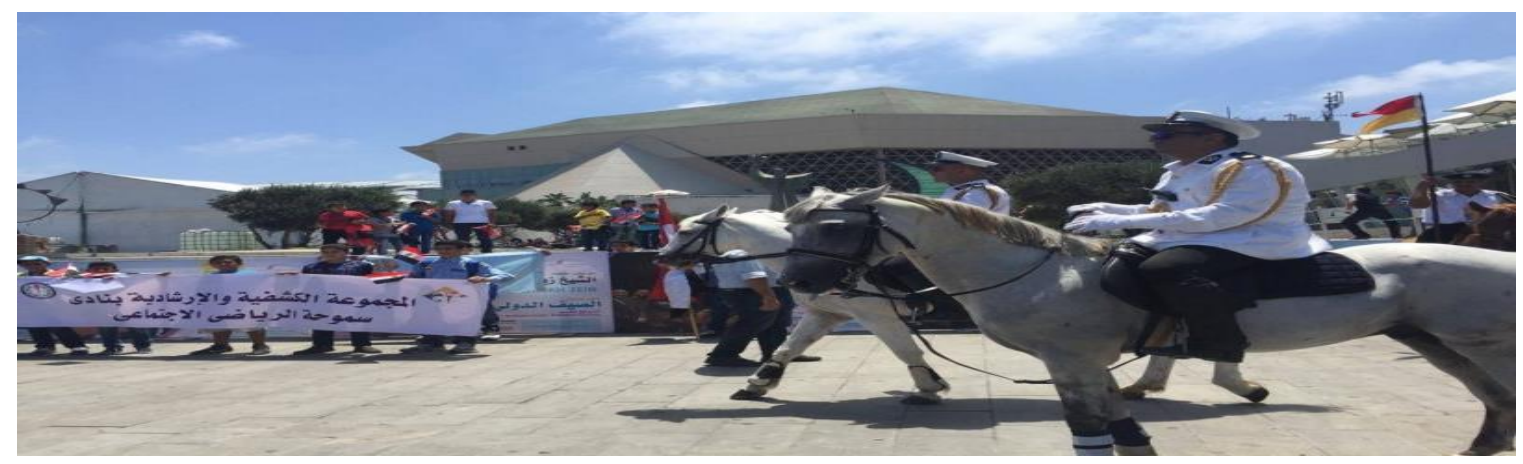

Source: http://www.elmaser-elgedid.com/wp-content/uploads/2016/07/resize.php_-89768x380.jpg.

Figure (22) Musical Concert for various Underground Musical Bands next to the Planetarium Science Center at BA Plaza"- Hawas Band, 17 July 2017

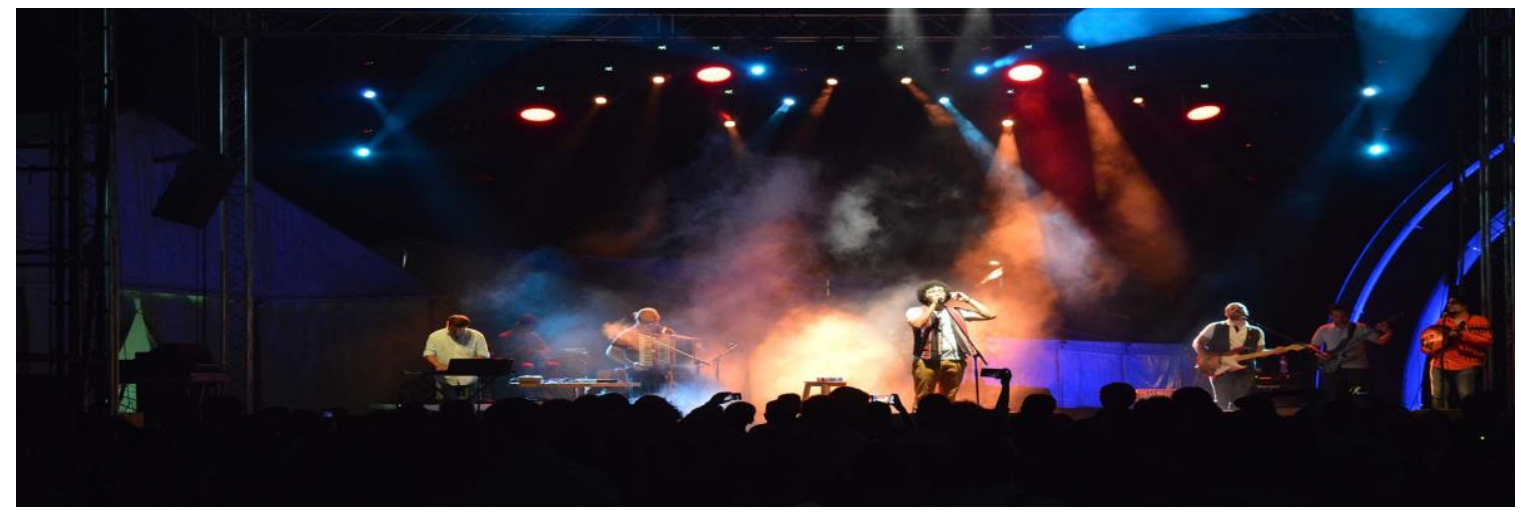

Source:https://weladelbalad.com/app/uploads/sites/16/2017/07/1500266777_893_133749_ds c_0335-800x600.jpg.

\section{The City as an Agent of Change; Preserving the City Spatial-Identity}

The visible interactive 'structure-agency duality' between structure and actors in reality within the case of Alexandria draws attention to Anthony Giddens's Structuration Theory. As a modern theorist who rejected the idea of dualism, Giddens's theory helps us understand how structure-agency works as part and parcel constructing each other in a mutual way (Layder, 2006). However, in order to get rid of "Giddens's flattening of the ontological terrain of society . . . and his one-dimensional vision of social reality," one should re-consider and re-vise the idea of the inner image and understanding of the self after severe changes, shocks, and traumas seeking ontological security as a "reflexive nature of self-identity" (Layder, 2006). That will lead our steps to ascertaining new theoretical insights. Following the previous argument, it can be said that the sportive initiatives taking place within the urban space of Alexandria streets, consist a new form of media that no longer correspond to the canonical definition of social movements. The 
form of a 'distinctive presence' made by different sportive movements can be seen in the absence of direct political confrontation in terms of collective action and street protest. Their sportive occupation of the Cornish street can be further interpreted using different analytical frameworks, i.e. we can understand them as "everyday forms of resistance" as weapons used by powerless groups within separated realms of practices (Scott, 1985).

Herein, the focus is on different grassroots movements that emerged in Alexandria within the last couple of years. All promoted the term "the right to city" as a concept that conveys the idea of Re-claiming /or/ Re-gaining the stolen public space that once was coined as being 'the people's space'. Some of these movements depend mainly on the spread of different sportive initiatives promoting for cycling, running, and jogging around the streets of Alexandria City in Egypt, i.e. Cycle Egypt, GBI-Alex Team, She Can Ride, and Alex Runners. Other movements took an academic and legislative form. i.e. Save Alex, Walls of an Exhausted City, Alexandria Does not see the Sea, and The Human and The City Center for Social Research (HCCSR). These movements could also be seen as a way to voice people's unspoken thoughts resembling "hidden transcripts" that is spoken directly and publicly in the face of power as a sort of "infrapolitics of the powerless," that does not contest subordination openly but create a new social space offstage (Scott,1990). In an environment where demolishing every open area and public-green spaces has become a systematic and palpable act, the goal is to discuss the everyday life practices of ordinary people in the endeavor of "refusing to exit" the socio-political stage. Furthermore, to understand how they are forcing the street politics that creates an exceptional form of the "art of presence" and "quiet encroachment," (Bayat, 2010), while asking can we define participants of these new practices as social actors. Can public messages in the form of graffiti, drawings and, writings be considered forms of social movements?

The case of the aforementioned sportive initiatives provides empirical standing point to understand how the uniqueness of their spatial surroundings of Alexandria with it waterfront fringe (Cornich), its urban design in parallel longitudinal streets, and its historical value as a cosmopolitan pot that encompasses different layers of history all have managed to create a spatial-cultural identity of Alexandrian people who refused the severe urbanization processes of their city that tried to wipe off the city historical identity as well. Their different initiatives are seen as a new form of urban resilience in preserving the city's heritage as an ancient-modern-cosmopolitan Mediterranean port. These sportive initiatives represent bottom-up interventions of brining the city together in face of severe urban transformations. They also represent a new form of grassroots social movements. In sociology, grassroots movements are defined as "collective attempts to promote or resist change in a society or group. . . some social movements are organized at the grassroots level by people directly affected by a particular social problem," (Encyclopedia of Sociology, 2000).

\subsection{Global Biking Initiative (GBI- Alexandria Team)}

One of the sportive initiatives of bringing the city of Alexandria together in the face of the brutal demolishing and fencing initiatives of the public open spaces of the city is the Global Biking Initiative- Alexandria Team (GBI-Egypt-Alexandria Team), (Figures \# 26-31). 
Figure (23) GBI Egypt Alex Team

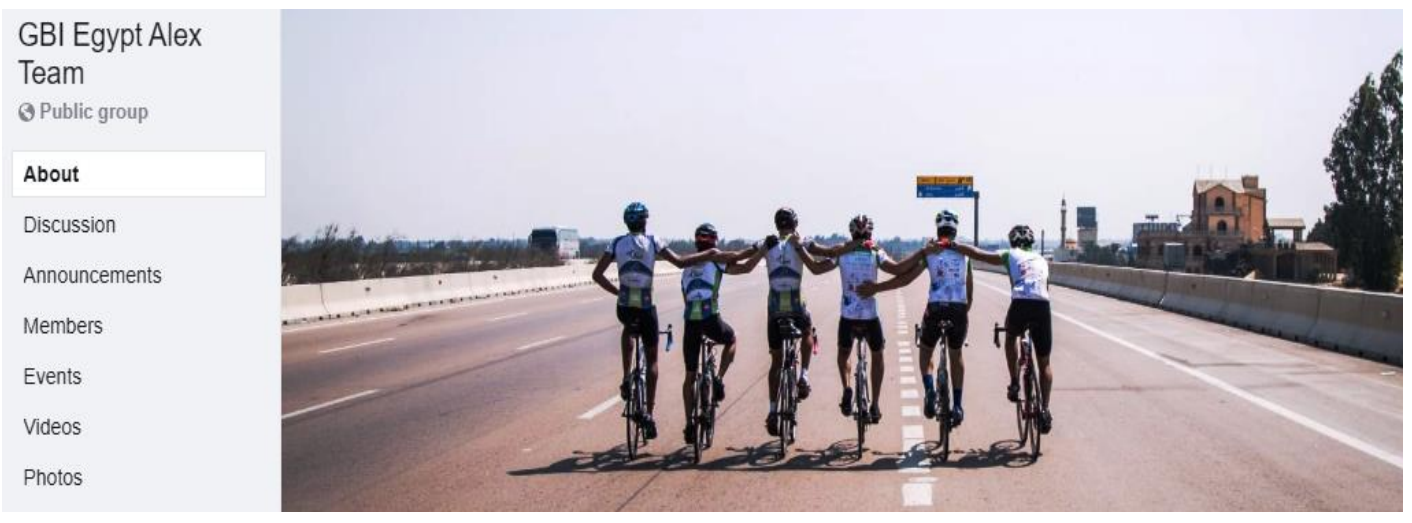

Source: https://www.facebook.com/groups/GBIEgyptAlex/about/

Figure (24) GBI-Egypt-Alexandria Team opening Photo

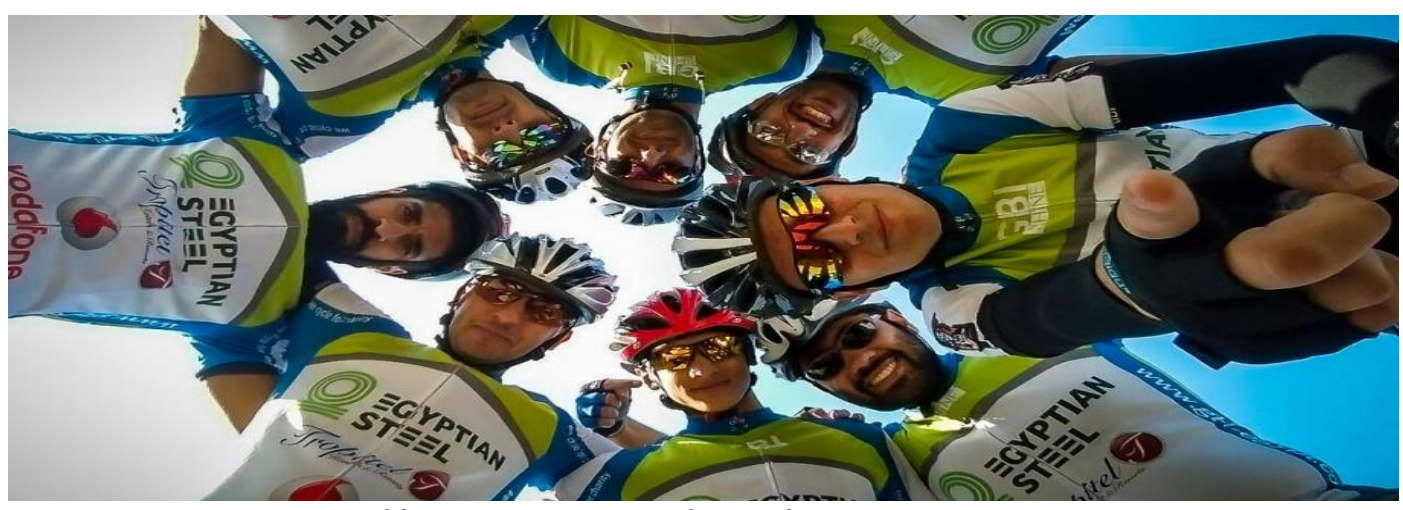

Source: https://www.strava.com/clubs/gbi-egypt-alex-team-113792.

Figure (25) GBI-Egypt-Alexandria Team exploring Egypt, and Promoting for Charity, Volunteering and Tourism in Luxor

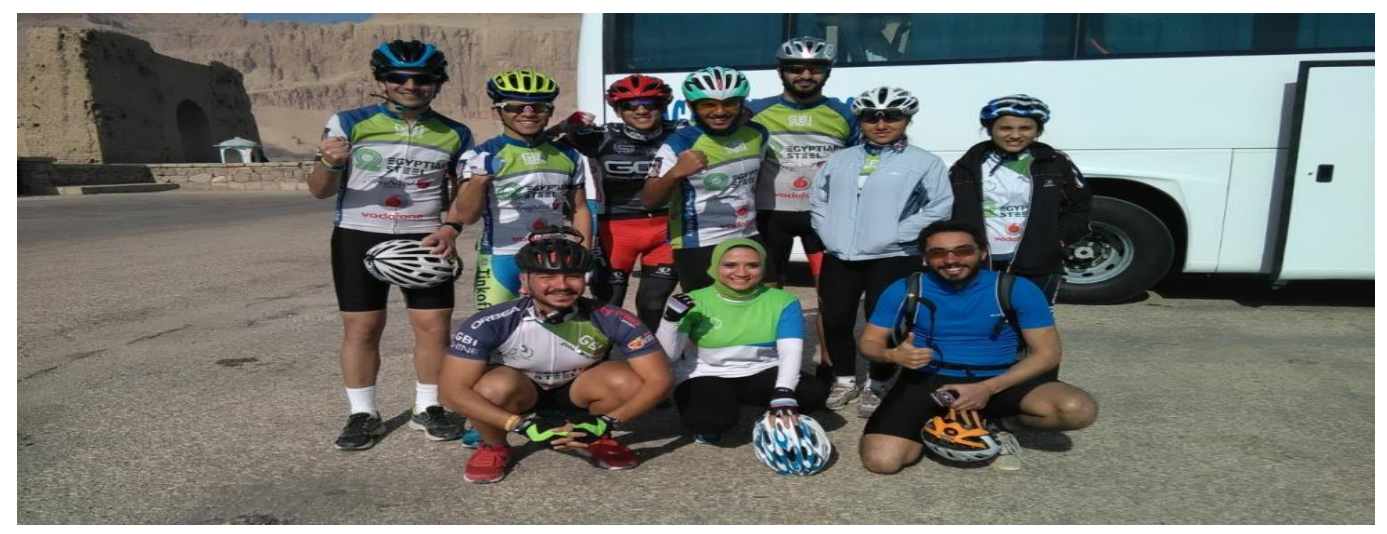

Source Credential: Haitham Malek. 
Figure (26) GBI-Egypt-Alexandria Team near El-Montaza Palace Promoting for Charity and Tourism

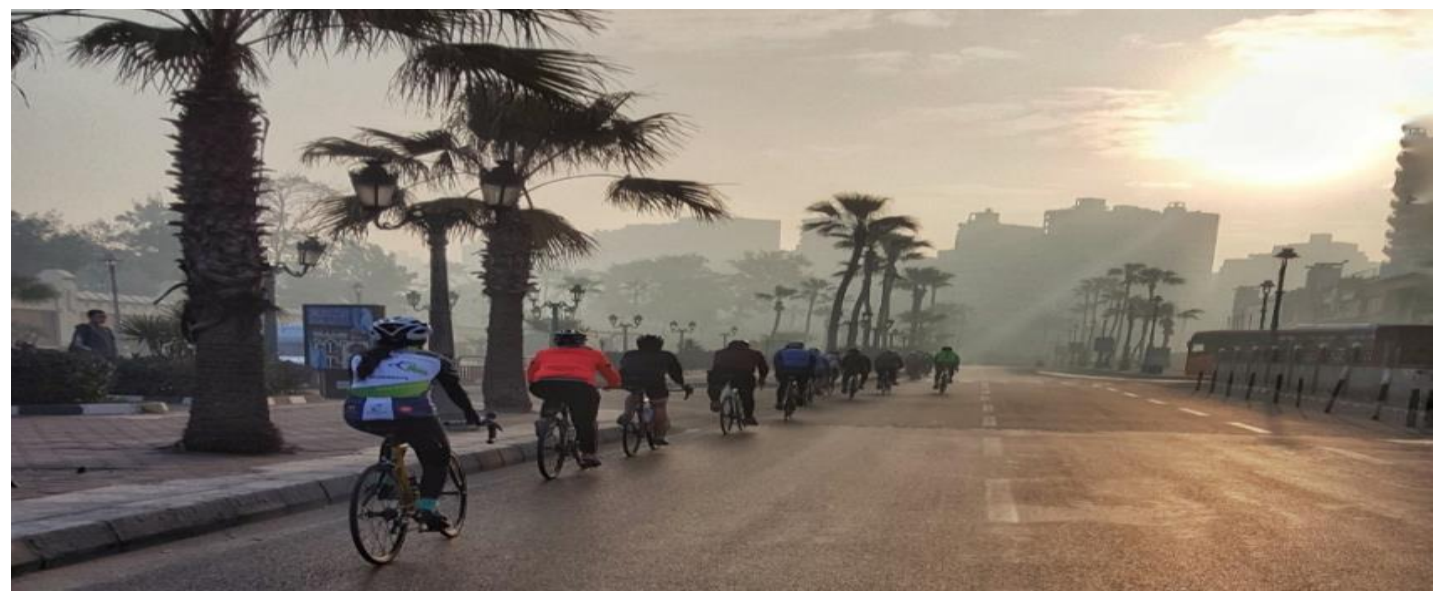

Source Credential: Abdelrahman Hammam.

Figure (27) GBI-Egypt-Alexandria Team on Alexandria-Cairo Desert Road

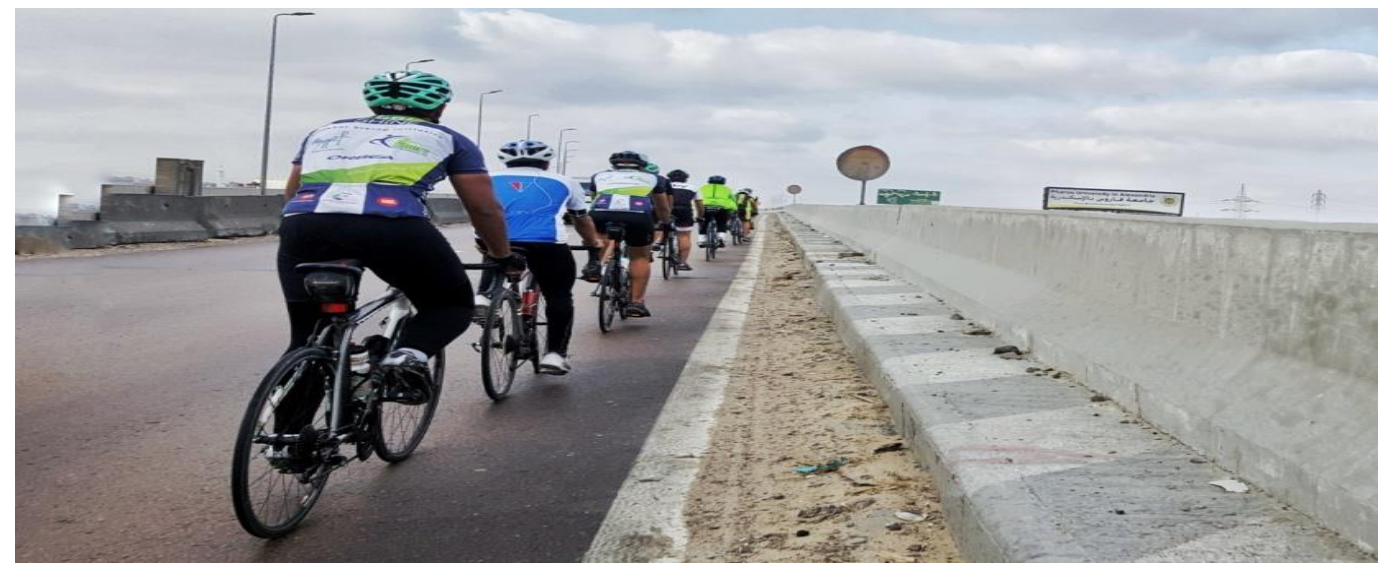

Source Credential: Abdelrahman Hammam. 
Figure (28) GBI-Egypt-Alexandria Team on Alexandria-Cairo Desert Road

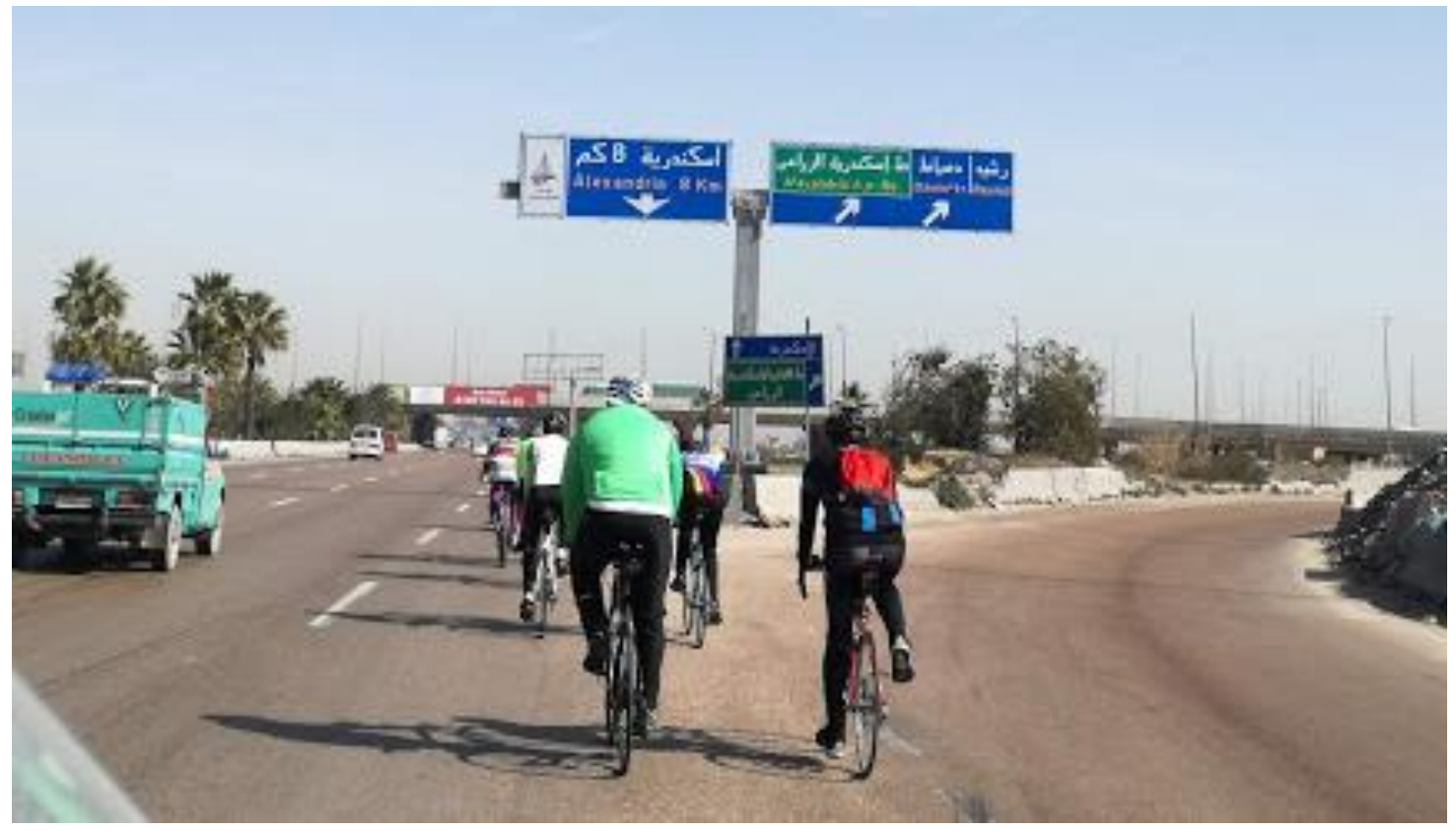

Source Credential: The Author, February 2019.

\subsection{Alexandria Runners}

The group was founded on February 2014 and identifies itself as aiming to "introduce Running as a sport to support a new healthy lifestyle and help our country to be a better place for living by sharing positive energy and collaborating with different parties for awareness runs and events". They bring the city together with no consideration to age, gender, or class differentiation aiming for a healthy lifestyle and a better quality of life in general (Figure\# 32).

Figure (29) Alex Runner's Logo aiming for a Better Quality of Life

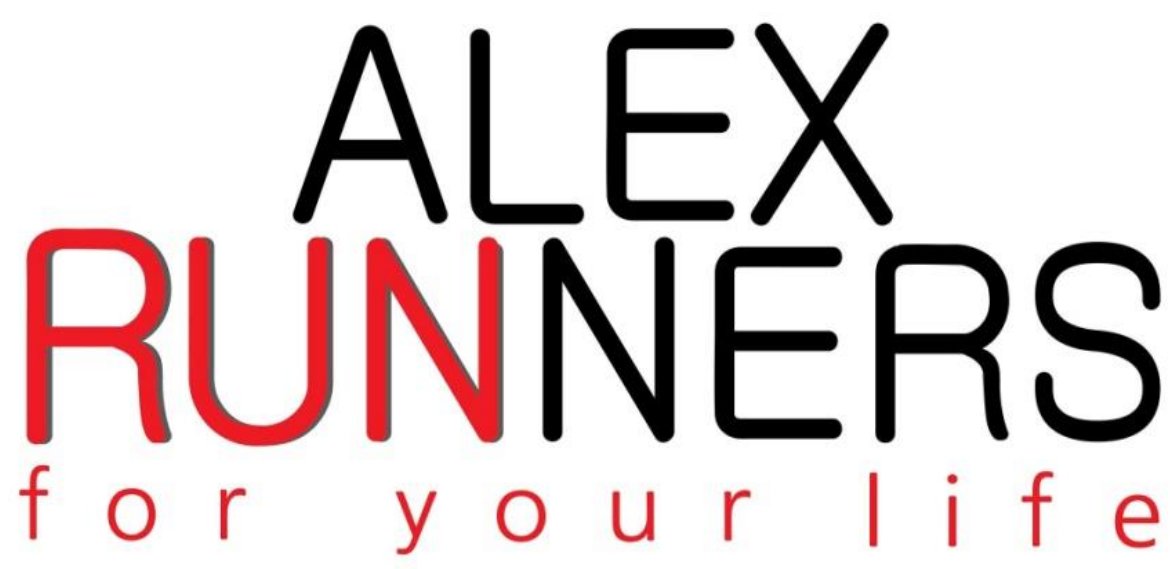

Source: https://www.facebook.com/AlexRunners1/. 


\subsection{Health Keepers}

Third example of the cycling sportive initiatives in Alexandria is a group of youth called Health Keepers who are "committed to providing its family members the knowledge, guidance, and opportunities needed to create an exceptionally supportive environment, that feels exactly like home, so that healthy living becomes more enjoyable and sustainable," (Figures \# 33-35).

Figure (30) Health-Keepers' Logo on their Facebook Page

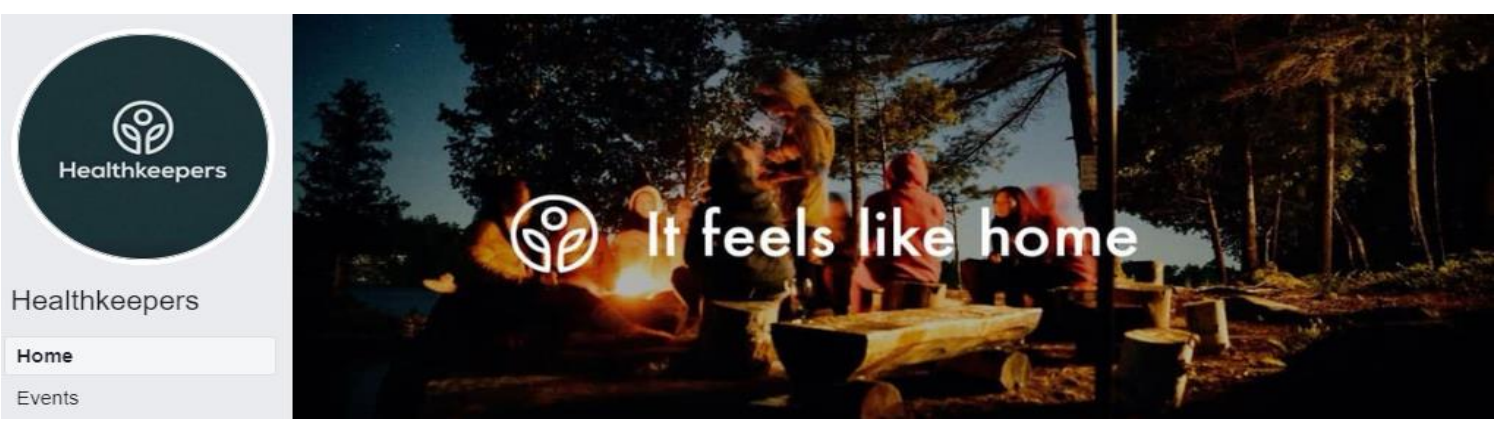

Source: https://www.facebook.com/Healthkeepers-2123278587916324/.

Figure (31) Health Keepers Group by the Beach in Bahari Area in Alexandria

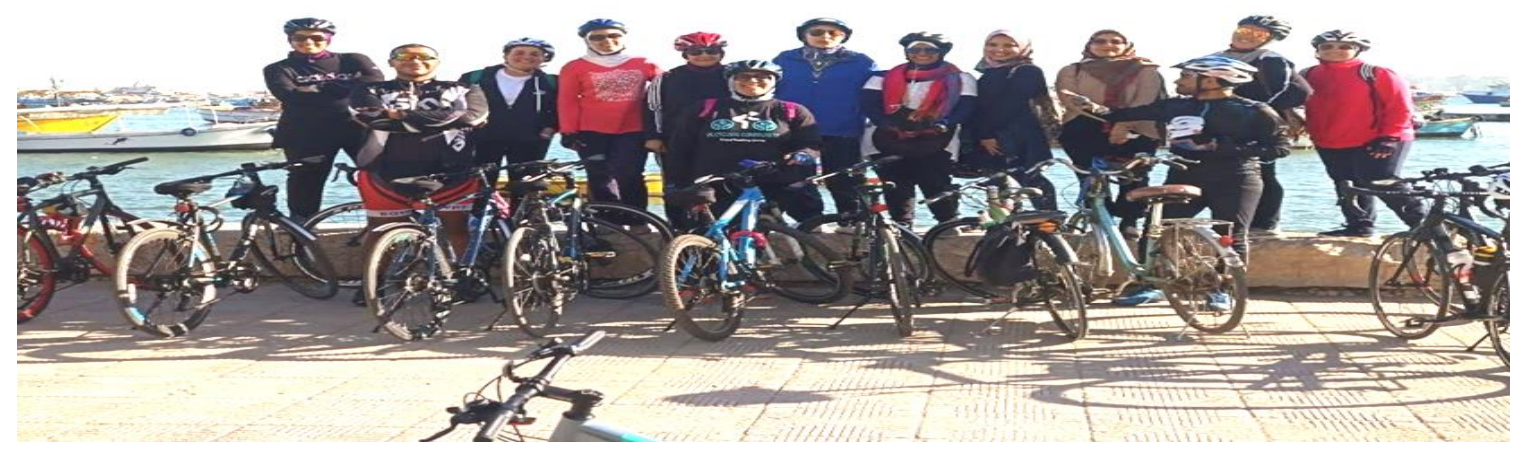

Source Credential: A Team Member.

Figure (32) Health Keepers Group by the Tram Line in Roushdy Area in Alexandria

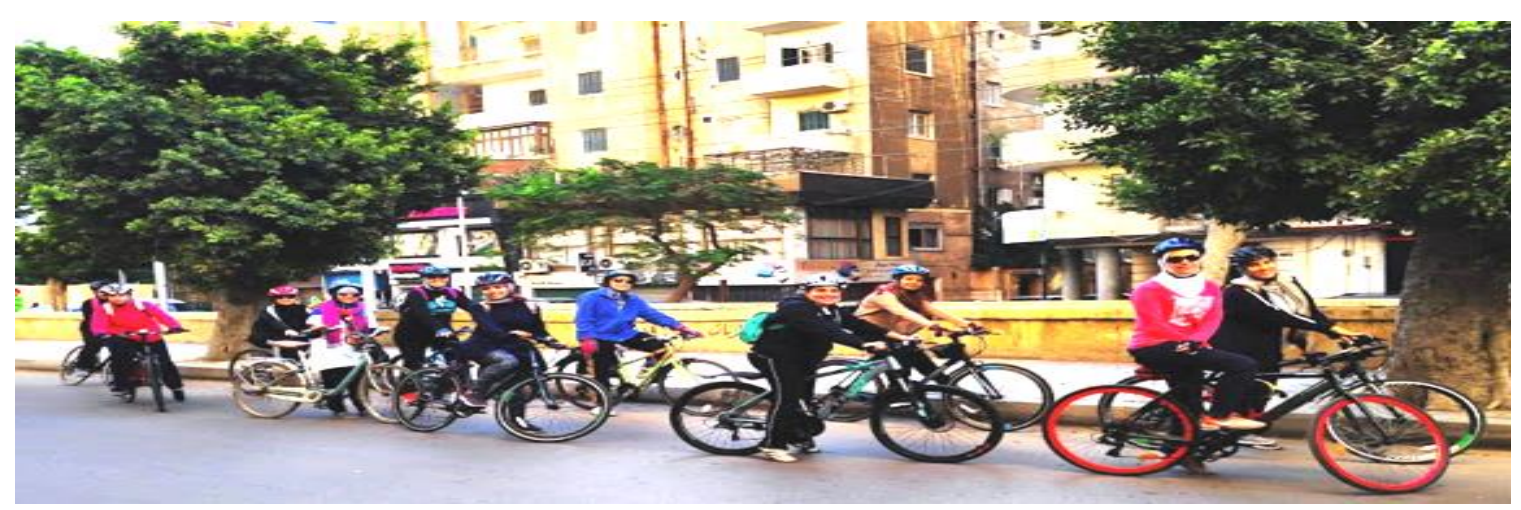

Source Credential: A Team Member. 


\subsection{Cycle Egypt.}

Another example is Cycle Egypt (Figures \# 36-37), the biggest cycling youth initiative in Alexandria that managed to bring a huge number of participants together on the city cornich every Friday's morning claiming their right of using the street in a safe, sustainable, unpolluted way of mobility (www.cycle-egypt.com).

Figure (33) Cycle Egypt's Cyclists exploring the Streets of their City Cornich in front of BAAlexandria

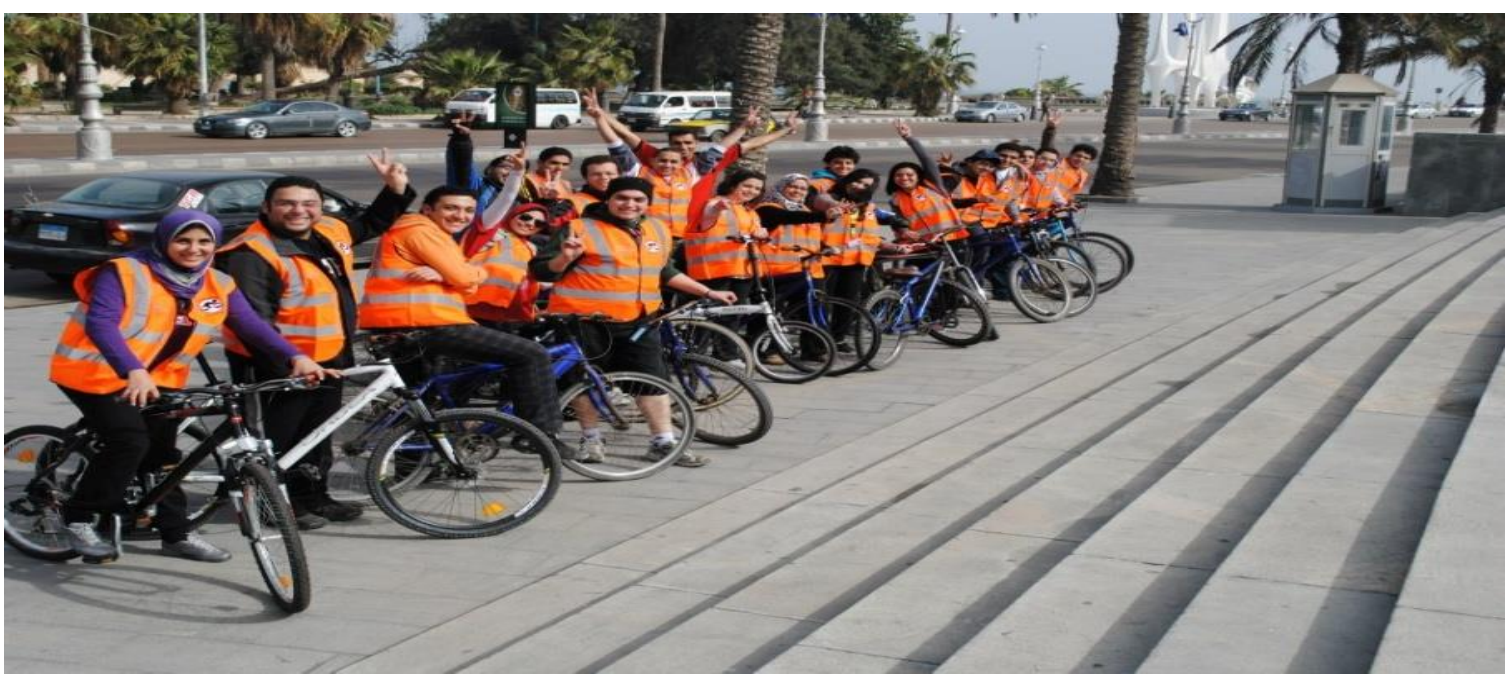

Source: http://www.cycle-egypt.com/

Figure (34) Cycle Egypt's Cyclists exploring the Streets of their City Ancient Area, Alexandria

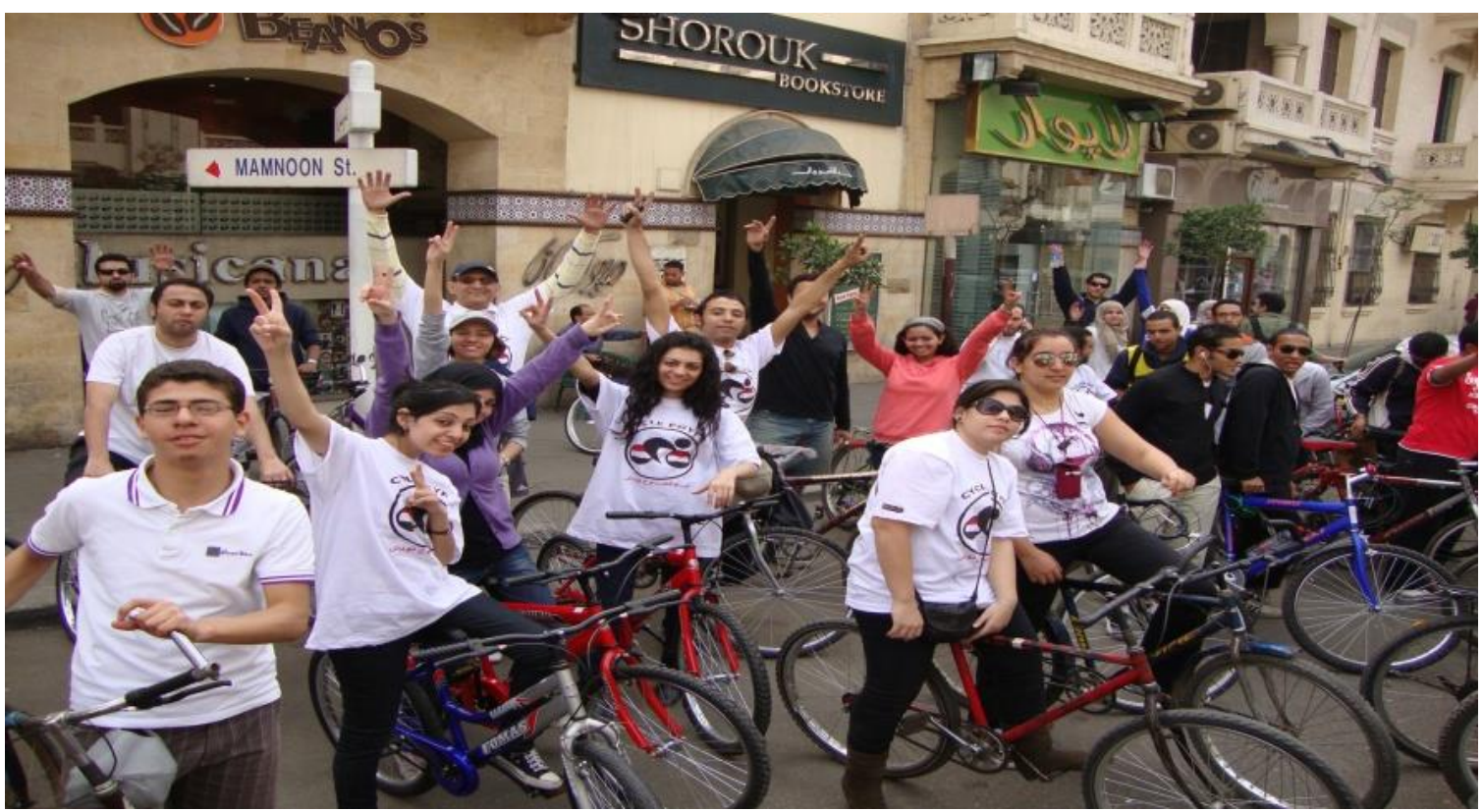

Source: http://www.cycle-egypt.com/ 


\subsection{Tabdeel}

The final example is Tabdeel initiative, which is defined by its founder Eng. Heba Ahmed Attia during an online interview on January 2, 2020 as being "an advocacy group that advocates and educates about the importance of biking and using bicycles as a nomotorized way of transportation. Within a futuristic vision of participating in the process of urban design of the society." The initiative's Facebook page highlights the etymological definition of the initiative's name, Tabdeel, in Arabic "can be translated to two verbs in English: 'Pedaling' and 'Change'... it is a call for cleaner, healthier and human centered cities especially in North African region." The founder of Tabdeel initiative confirmed during the interview that they managed to launch some sort of a cooperation between them , as a grass-root movement with other civil society initiatives (i.e. Friedrich Ebert Stiftung Egypt Office, Future Earth Foundation), and the state urban planners (Figures\#3845). Attiah said that "we managed to work as a link between the bicycle-user society and individuals in Egypt and different governmental apparatuses...we were using urban design language with them in all conferences and roundtables we have been invited to...such a case did not necessarily lead to a direct cooperation with the government; however, it guaranteed a primary representative role for an initiative that advocate for bicycles use, bikers' safety, and friendly designed roads for bicycles," (Attia H., online interview, January 2, 2020).

Figure (35) Flayer of a Roundtable on Urban National Policy, organized by the Ministry of Housing, Utilities, and Urban Communities, UN-HABITAT for better future, and the General

Organization for Physical Planning, on October 21, 2019

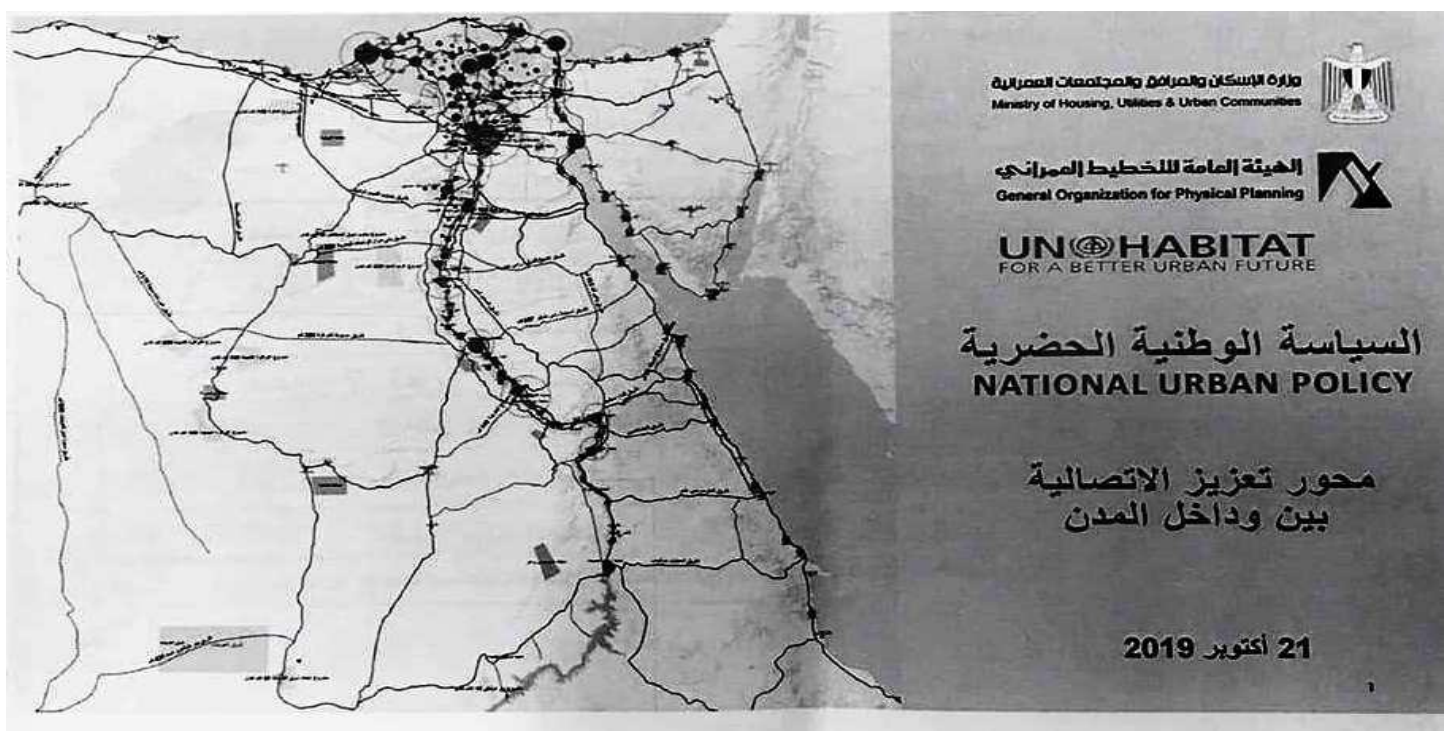

Source: Tabdeel Facebook page: https://www.facebook.com/tabdeel4/ 
Figure (36) Tabdeel Initiative attends the Roundtable on Urban National Policy

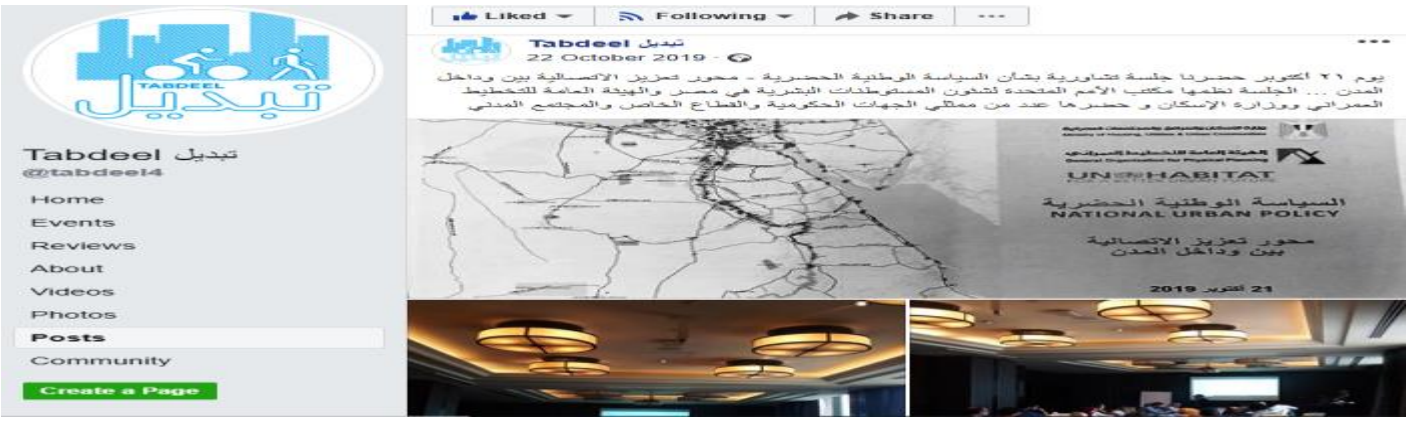

Source: Tabdeel Facebook page: https://www.facebook.com/tabdeel4/

Figure (37) Flyer of the Conference 'African Cities- Engine for Sustainable Development, 18-20 June 2019,' under the auspices of The Ministry of Local Development, in cooperation with the United Nations Human Settlements Program (UN-Habitat), the European Union, and a number of international development organizations, including the United Nations Development Programme (UNDP), the United Nations Population Fund and the German Agency for International Cooperation (GIZ)

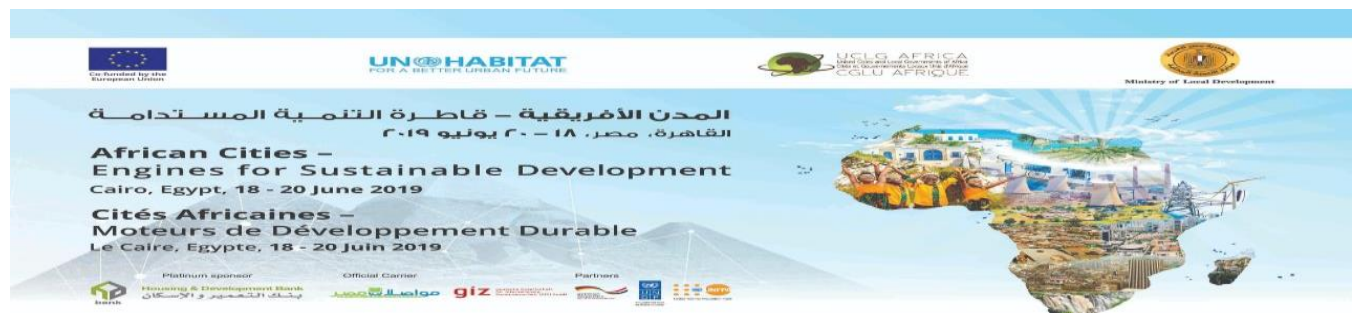

Source: Tabdeel Facebook page: https://www.facebook.com/tabdeel4/ \& Egypt-UNDP page: https://www.eg.undp.org/content/egypt/en/home/presscenter/pressreleases/2019/-africancities--engines-for-sustainable-development--concludes-.html.

Figure (38) Tabdeel Initiative attends the Conference 'African Cities- Engine for Sustainable Development, 18-20 June 2019

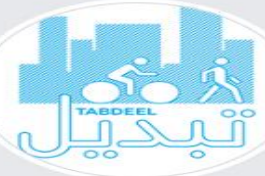

Tabdeel تبديب (c) tabdeel4

Home

Events

Reviews

About

Videos

photos

Posts

Community

Create a Page
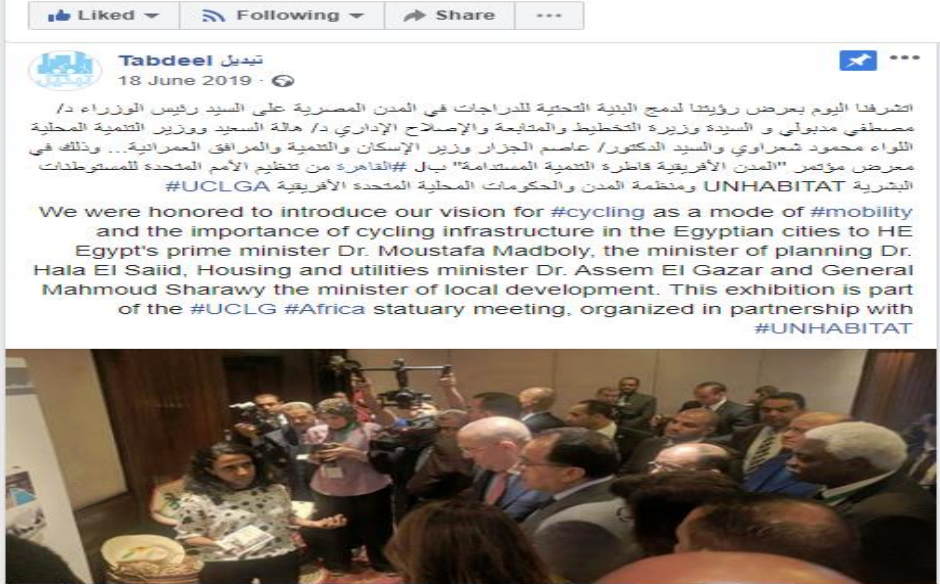

Source: Tabdeel Facebook page: https://www.facebook.com/tabdeel4/ \& Egypt-UNDP page: https://www.eg.undp.org/content/egypt/en/home/presscenter/pressreleases/2019/-africancities--engines-for-sustainable-development--concludes-.html. 
That being said, it is important to highlight the crucial role played by different bottom-up initiatives in raising the awareness of what was mentioned previously as "Tisseron's Societal-Resilient System," that spreads a new culture of mobility and environmentfriendly-transportation initiatives like Tabdeel. Within the same lines, Tabdeel managed to link with other movements in order to spread the culture of cycling/ bicycles as a nonmotorized way of mobility and a sustainable green solution for the traffic jam within different Egyptian cities. The initiative also managed to hold a workshop at BA during August 2018 along with interactive-cycling Lab to help the public imagine the cycling routs on Alexandria Corniche on April 2019 (Figures\# 42-44).

Figure (39) Logo of Tabdeel Initiative
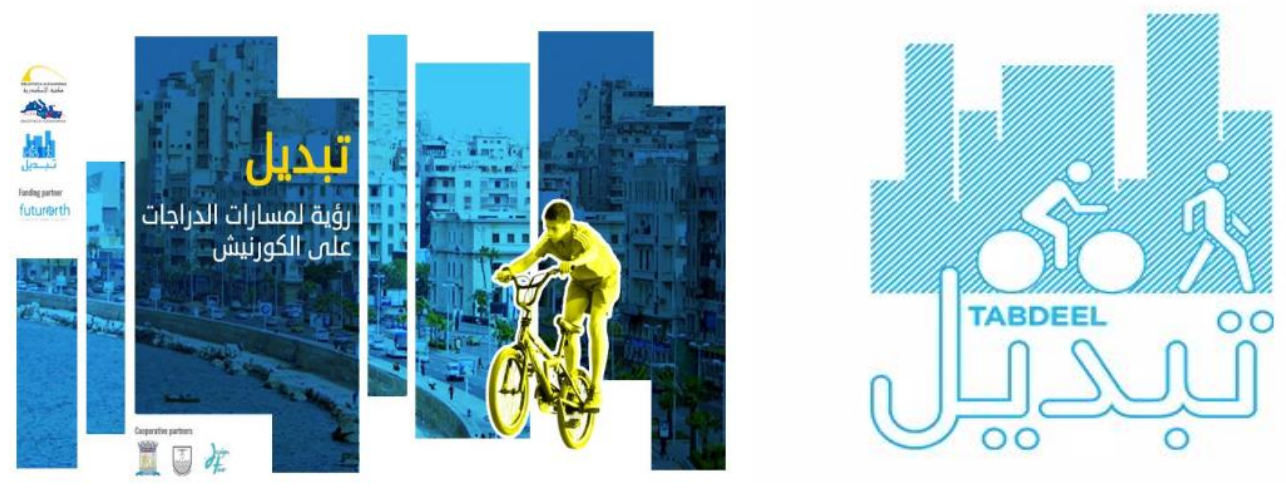

Source: https://www.facebook.com/tabdeel4/.

Figure (40) Tabdeel Interactive-Cycling Lab at Bibliotheca Alexandrina (BA) on 15 ${ }^{\text {th }}$ April, 2019

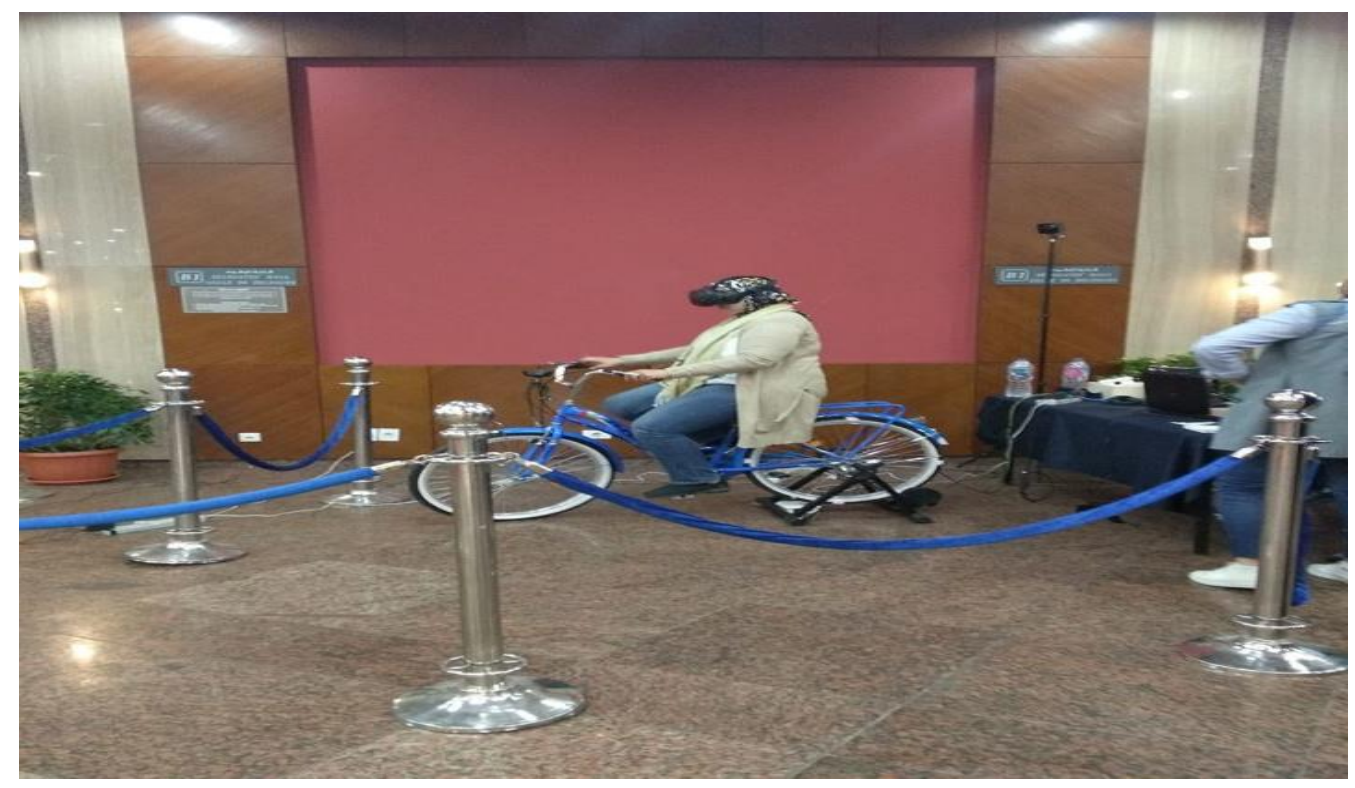

Source Credential: Asmaa Abd Allah. 
Figure (41) Tabdeel reaching out to other Egyptian Cities with various workshops and courses, i.e. Port Saied city and Alexandria City; as the initiative continues its efforts of spreading the awareness of non-motorized mobility with a workshop in Alexandria City about "The Culture of Bicycles" in 17-18 January, 2020
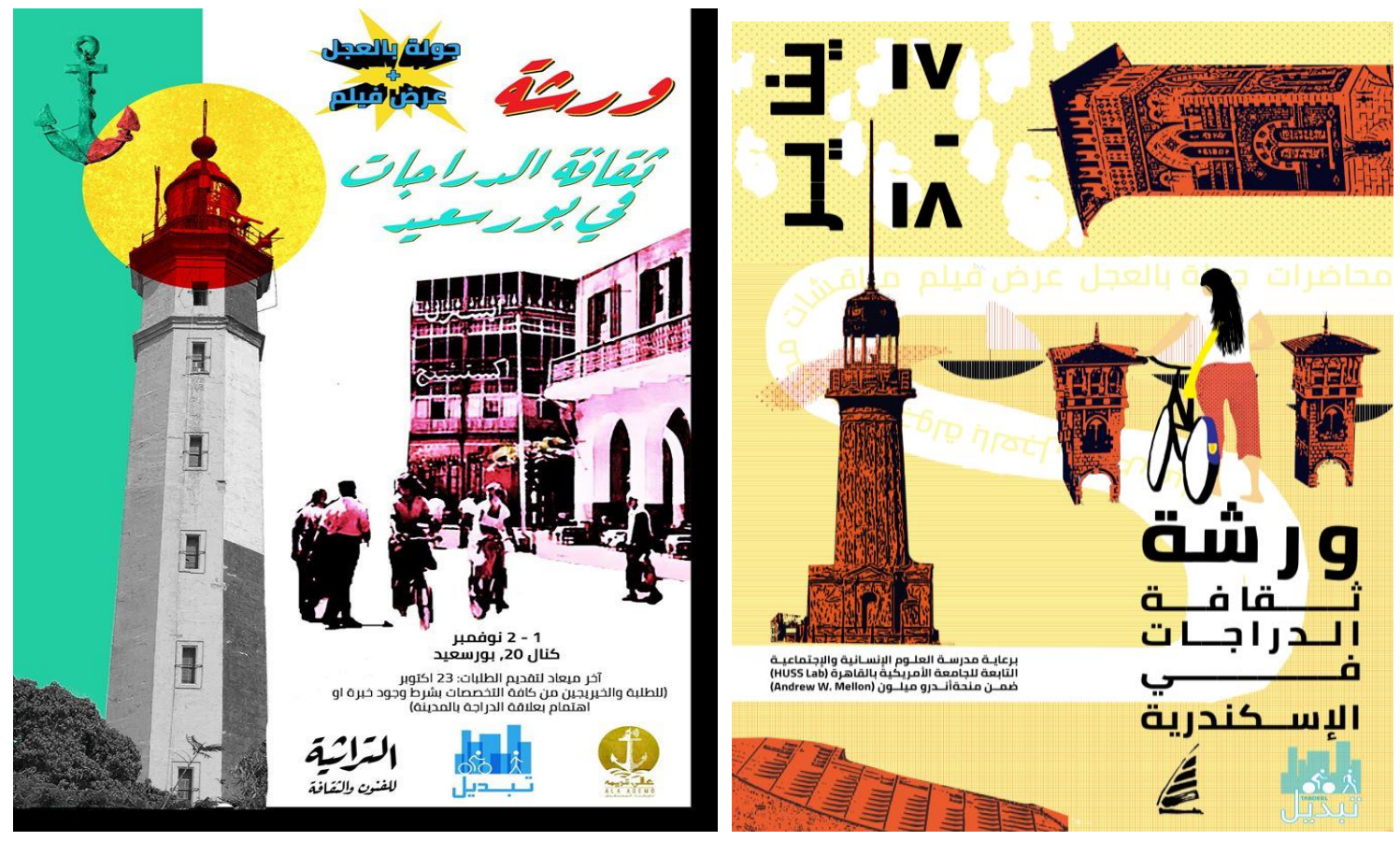

Source Credential: Omar Aboutaleb.

\section{Discussion- the Right to the City; A New Form of Human Rights}

"While we occupy, claim and explore the city and its spaces, we interact bodily with objects and spaces on a daily basis...we are constantly in a state of transition between things...this active engagement during the transit(ional) situation, the act of producing, consuming and using the urban locations, constitutes the starting point to characterize the in-between place," (Luz, 2006).

David Harvey argues that: "The right to the city is far more than the individual liberty to access urban resources. . . it is a right to change ourselves by changing the city collectively. . .the freedom to make and remake our cities and ourselves," (Harvey, 2008). In this vein, this paper represented the term 'the right to city' as a concept that conveys the idea of Re-claiming /or/ Re-gaining the stolen public space that once was coined as being 'the people's space'. It also represented a new sociological perspective about how people claim their own spatial space and practice their right to the city as a new type of human rights. The paper provided an analysis of new forms of urban-grassroots social movements that represent a sort of bottom-up intervention that depend mainly on the spread of different sportive initiatives promoting for cycling, running, and jogging around the streets of Alexandria City in Egypt. It is more about how people claim their own space. They practice the right to public space as a new form of human rights. Some of these movements depend mainly on the spread of different sportive initiatives promoting green and sustainable mobility, cycling/ biking, running, and jogging around the streets of Alexandria City in Egypt, i.e. Cycle Egypt, GBI-Alex Team, She Can Ride, and Alex Runners. 
Some of these movements cooperated with other grassroots movements taking a legislative detour through "The Human and the City Center for Social Research (HCCSR)" that started to: gather academics, architects, political activists together, and arrange public lectures of raising awareness. They went a step further when they went to the court to raise a case against the state representatives who demolished every public garden and public space in Alexandria along with fencing the famous Alexandria Corniche. Considering the state's recent initiative of "A Bike for each Student," do we have the culture of 'safety first' before letting young youth ride bikes shoulder to shoulder with cars, microbuses, taxies, and buses? Do urban planners and decision-makers consider bike lanes as a form of human rights? The Egyptian state is promoting for the establishing of different forms of Future Cities, i.e. Al-Alameen city, and the New Administrative Capital, so what about the old cities? Taking the city of Alexandria as a case study of that, it can be noticed that the state followed different strategies; of what can be called: "street evacuation policy" of people and re-occupying it using different state apparatuses not just on the spatial level, but on the legislative level as well. As The people were prevented the right to their own cities and public spaces, either by closing, fencing, or demolishing any garden and open public space in the city and replace it by cement buildings, restaurants, and cafeterias. However, it is so evident that the people of Alexandria City managed to launch different informal initiatives and grassroots-sportive movements to create a bond with their city and help preserve part of its spatial-identity and cultural heritage within an ever-changing public space on which they have no control. Finally, the special case of Alexandria Library forces us to inquire about the people's right to their cities. Do urban planners and decision makers consider 'access to public areas' as a form of human rights? Do we have this culture of maintaining public access to public spaces within the dominant mindset of the political mainstream within the Arab world?

Many studies have shown that one of the greatest challenges that face urban planners and policy makers while designing urban projects is the way in which they plan strategically for these projects starting with the location decision and the promotion for these projects. Many steps have to go line with the objectives of the adopted urban design policies (Chang et. al. 2010). In other words, the establishment and development of urban projects requires a rational, careful, strategic, and realistic planning reflects both the real needs and potentials of the community. Such goals will require efforts to create a climate conducive to the continuity of these projects including: follow-up of the action plans, continuous assessment of the achieved goals, and the transparency and accountability which requires transparency and openness. A pertinent study by Ali Alraouf argued that the chaotic national planning in Egypt has led to the creation of luxuriant fancy gated communities that service certain segments of the society. The author coined the phenomenon as being "Negative Chaos" that emerged because of the launching of sequential unclear policies. The phenomenon has led to different negative effects such as: lack of trust between marginalized groups and the state as they have lost confidence in their state. The phenomenon also has led to lack of sense of belonging to the place and to the absence of social justice (Alraouf, 2016). 


\section{Conclusion and Recommendations}

Within a drastic unstable global sphere, bringing a city together requires industrious efforts as cities were not born overnight. Every city has its own historical trajectories; so how to adapt to the global transformations without losing their identity, their history, and most importantly their social cohesion? Tackling these issues requires a solid case where urban resilience and heritage preservation efforts are visible for study. Alexandria City, as situated in the south, provided different connotations and new solutions from a sociological point of view of some resilient urban system solutions that may help answer the question of: How the future city could be resilient? In this paper, the researcher examined Alexandria as a resilient city investigating whether it has managed to build a sense of belonging to people's spatial surroundings while pursuing sustainability or not. Accordingly, different theses may be highlighted for a better concluding of the spatial transformations within urban spaces in Egypt which affected some of the social dimensions in regard to citizens' access to different urban areas and spaces. Thesis one: sustainable development paradox in the relationship; it refers to the paradox between sustainable development policies and their implementation in reality, in terms of favoring the economic growth regardless of the socio-cultural and human dimensions of development. Thesis two: security reasons for protection! (to create a space that excludes outsiders); it reflects an official discourse of a governmental desire to limit the public access to these knowledge-based-cultural hubs and their spatial areas for security reasons, or to grant access to a certain spectrum of people that could include foreign investors only, on the pretext that limited public access will ensure security and will lead to more industrial and economic boom which will contradict the need for publicity and the promotion for the 'success of the state' achieved through these k-based projects that are kept hidden from public. Thesis three: Location Decisions of the knowledge-basedcultural hubs that was designed for attracting the creative class and certain knowledge workers); this thesis is about the creation of an environment (economic, residential, social and cultural); to attract certain citizens with certain potentials and skills to work at these k-based precincts while excluding the majority of citizens who might be a 'source of disturbance and insecurity' to the creative class members (Krueger and Gibbs, 2007). Regardless the different hypotheses and theses, one outcome is related to the "limitation of public access to these places and development areas," which could be coined as the "concealment of these development projects and spatial areas". It is globally known that our contemporary world is going through crucial changes; and as a result of Globalization many transformations affected the human society. After discussing cycling as a form of sustainable urban transport that was initiated within the city of Alexandria through different forms of grassroots movements that aim to increase the quality of urban life it can be concluded that these sportive initiatives represent a sort of bottom-up intervention to biking as a social movement, no one listens, so may be to create a movement that will exercise pressure to make their needs heard and seen.

Finally, the author recommends and call within the academic sphere for, more interdisciplinary researches are needed in order to investigate the transformations within the urban space, forms of participation, and claims of the city within the current Africanglobal context. This could help presenting new perspectives of the type of urban socio- 
cultural transformations taking place in some cities in Egypt, and shed light on new participatory activities at modern Egypt while answering a pertinent question of: How to build a theory out of these topics for a better understanding of reality? The city of Alexandria with its great history and heritage as a cosmopolitan city deserves more academic exploration of the nature of participatory change that are linked to the sociocultural transformations that oppose the authoritarian transformations taking an updown perspective. Finally, presenting this paper on the premises of Alexandria Library ii draws attention to the important role played by the library as a cultural hub and a catalyst of development within the city of Alexandria to gather all individual initiatives of heritage preservation and urban resilience under its umbrella in order to combine streetmovement with the academic perspectives of studying the city reaching better sustainable solutions for a better future.

\section{Acknowledgement}

The author would like to thank Dr. Ryo Terui (Central Saint Martins, University of the Arts London) for generously sharing his work on the Actionality Mapping which helped the researcher in building a solid methodological tool of visual storyboarding within her research and ascertaining new theoretical insights within the discipline of urban sociology. Many thanks also to Dr. Tricia Austin (Central Saint Martins, University of the Arts London) for her insights and modifications after reading the first draft of this paper and for sharing some of her work on Actionality Theory. I also would like to thank my colleagues of the participants -Mohamed Yousef, Amira Elrakaiby, and Alaa Hikal- at Dr. Ryo Terui's workshop "Design and Society Seeking Post Design Thinking through Visual Methodology, December 2-3, 2019" at the Egyptian-Japan University of Science and Technology (E-JUST) for their insights in building the research Actantial Map. Thanks also to GBI-Alexandria team members, Abdelrahman Hammam (a professional photographer and a GBI member) and Haitham Malek (a graphic designer and a GBI member) for generously sharing some of their photos of $\mathrm{GBI}$ team to be used within this research paper. I would like to thank Ms. Asmaa Abd-Allah, a Tabdeel member for sharing some of her photos about the imitative. Last but not least, thanks to Eng. Heba Ahmed Attiah, founder of Tabdeel initiative for her time reading the first draft of this paper and applying an online interview with the researcher on January 2, 2020, to highlight some of Tabdeel's achievements reaching out at all levels within the Egyptian society and beyond; to raise awareness and advocate for using bicycles as a sustainable way of transportation.

\section{References}

Alraouf, A. (2016). Creative Urban Chaos in Cairo's Spaces after the January 2011 Revolution; the Nile Bridge and Maidan Tahrir. Omran Periodical, Arab Center For Research And Policy Studies (ACRPS), 5(18), 33-62. Accessed: April 18, 2018. Retrieved from https://omran.dohainstitute.org/en/issue018/Pages/art02.aspx.

Austin, T. (2020). Narrative Environments and Experience Design: Space as a Medium of Communication. New York: Routledge.

Barthel, P., Davidson, L., \& Sudarskis, M. (2017). Alexandria: Regenerating the City- A contribution based on AFD Experiences. Paris: Agence Française de Développement (AFD), lain Whyte (ed.). 
Accessed: April 18, 2018. Retrieved from https://intaaivn.org/images/cc/Transmed/AlexandriaContribution.pdf.

Bayat, A. (2010). Life as Politics: How Ordinary People Change the Middle East (2nd ed.). Amsterdam: ISIM and Amsterdam University Press.

Borgatta, E., \& Montgomery, R. (2000). Grassroots Movement. In Encyclopedia of Sociology (2nd ed., Vol. 5). New York: Macmillan Reference USA.

Chang, S., Lee, Y., Lin, C., \& Hu, T. (2010). Consideration of Proximity in Selection of Residential Location by Science and Technology Workers: Case Study of Hsinchu, Taiwan. European Planning Studies, 18(8), 1317-1342. doi: 10.1080/09654313.2010.490651.

El-Tabbakh, M. (2014). The World We Never Knew. Cologny, Switzerland: AAHA-Amicale Alexandrie Hier et Aujourd'hui. Accessed: April 18, 2018. Retrieved from http://www.aaha.ch/cahiers/aaha-cahier-74-may.pdf

Escoffey, C., \& Cavoura, F. (2012). Ancient Alexandria. Alexandria, Egypt: Bibliotheca Alexandrina Cataloging-in-Publication Data. (ISBN 978-977-452-200-0). Accessed: May 2, 2019. Retrieved from https://www.bibalex.org/Attachments/Publications/Files/201303201500376555_AncientAlexan dria.pdf.

Grosz, E. (2001). Architecture from the Outside: Essays on Virtual and Real Space. USA: Massachusetts Institute of Technology.

Harvey, D. (2008). The Right to the City. New Left Review, 53, 23-40. Accessed: May 2, 2019. Retrieved from https://newleftreview.org/issues/II53/articles/david-harvey-the-right-to-thecity.pdf

Harvey, D. (2012). Rebel Cities: From the Right to the City to the Urban Revolution. London- New York: Verso Publications.

Hébert, L. (2006). The Semiotic Square. in Louis Hébert (dir.), Signo [online], Rimouski: Quebec. Retrieved 18 January 2020, from http://www.signosemio.com/greimas/semiotic-square.asp

Krueger, R., \& Gibbs, D. (2007). The Sustainable Development Paradox: Urban Political Economy in the United States and Europe (Introduction: Problematizing the politics of sustainability: 1-11). New York: The Guilford Press.

Layder, D. (2006). Understanding Social Theory (2nd ed.). London: SAGE Publications Ltd.

Luz, A. (2006). Places In-Between: The Transit(ional) Locations of Nomadic Narratives. Place And Location Studies In Environmental Aesthetics And Semiotics Date, 5, 143-165. Accessed: December 1, 2017. Retrieved from http://www.eki.ee/km/place/pdf/kp5_11_luz.pdf.

Martin-Moreau, M. and Ménascé, D., 2018. Urban Resilience: Introducing this Issue and Summarizing the Discussions. The Journal of Field Actions, Field Actions Science Reports, Special Issue "Resilient Cities," No. (18): 6-11. Accessed: December 15, 2018. Retrieved: https://journals.openedition.org/factsreports/4629.

Meinardus, O. (2002). Two Thousand Years of Coptic Christianity. Cairo: The American University in Cairo Press.

Parsons, A. (2019). Narrative Environments as Actant Networks. Unpublished Lecture, CSM, October 2019, Central Saint Martins, University of the Arts London. 
Sassen, S. (2010). The City: Its Return as a Lens for Social Theory. City, Culture And Society, 1, 311. doi: 10.1016/j.ccs.2010.04.003.

Scott, J. C. (1985). Weapons of the Weak: Everyday Forms of Peasant Resistance. USA: Yale University Press.

Scott, J. C. (1990). Domination and the Arts of Resistance: Hidden Transcripts. USA: Yale University Press.

Serageldin, I. (2008). Cultural Heritage and Development in the Arab World. Editors: Fekri Hassan, Aloisia de Trafford, Mohsen Youssef (eds.). Alexandria, Egypt: Bibliotheca Alexandrina. Retrieved from https://www.bibalex.org/arf/en/gra1106_df_20081102_book.pdf.

Sirry, A. (2018). Alexandria: Development Challenges of a Coastal Second City. Cairo and Associate of Metropolis: Housing and Building National Research Center (HBRC) and Barcelona Centre for $\begin{array}{llll}\text { International Affairs } & \text { (CIDOB). from }\end{array}$ https://www.cidob.org/en/content/download/69979/2100878/version/1/file/145158_AZZA\%20SIRRY.pdf.

Terui, R. (2019). Design and Society Seeking Post Design Thinking through Visual Methodology. Unpublished Workshop, December 2-3, 2019, The Egyptian-Japan University of Science and Technology (E-JUST) Alexandria.

Turchiarulo, M. (2009). Building Styles brought to Egypt by the Italian Community between 1850 and 1950: The Style of Mario Rossi. In Proceedings of the Third International Congress on Construction History. Germany: Cottbus. Retrieved from http://www.bma.arch.unige.it/PDF/CONSTRUCTION_HISTORY_2009/VOL3/TURCHIARULOMariangela_paper-revised_layouted.pdf.

UN-Habitat \& Urban Resilience Hub (2019). What is Urban Resilience?. UN-HABITAT for a Better Urban Future. Accessed: 30 November 2019. Retrieved: http://urbanresiliencehub.org/what-isurban-resilience/.

United Nations Population Fund (UNFPA) and the Ministry of Planning and Economic Development (MPED) (2018). Egypt National Report: Addis Ababa Deceleration on Population and Development in Africa beyond 2014 (AADPD+5), June 2018. Retrieved: https://egypt.unfpa.org/sites/default/files/pub-

pdf/Egypt\%20National\%20\%28AADPD\%2B5\%29\%20Report\%20MidNov18\%20\%281\%29.pdf \& https://www.citypopulation.de/en/egypt/admin/02_al_iskandariyah/

Weber, M. (1969). The Nature of The City. In R. Sennett, Classis Essays on the Culture of Cities. New Jersey: Prentice-Hall Inc. USA.

\section{Notes}

i Please refer to: Austin, T. (2020) Narrative Environments and Experience Design: Space as a Medium of Communication. New York: Routledge; Parsons, A. (2019) Narrative Environments as Actant Networks, unpublished workshop, Lecture at CSM, October 2019, Central Saint Martins, University of the Arts London.

ii This paper was also accepted to be presented in "The Path to City Resilience International Conference", MSA University- October University for Modern Sciences and Arts, Faculty of Engineering, 22-23 March 2020, Bibliotheca Alexandrina. 